\title{
Atmospheric Mining in the Outer Solar System: Aerial Vehicle Mission and Design Issues
}

51 $1^{\text {th }}$ AIAA/ ASME/ SAE/ ASEE Joint Propulsion Conference and Exhibit Propulsion and Energy Forum Orlando, FL

Bryan Palaszewski NASA Glenn Research Center Cleveland $\mathrm{OH}$ July 2015 


\section{Introduction}

- Why atmospheric mining?

- Resource capturing: helium 3, hydrogen, helium.

- Aerospacecraft as uninhabited aerial vehicles (UAVs), cruisers for weather reconnaissance, monitoring, etc.

- Engine issues.

- Gas core engines, closed cycle.

- Lifetime(s).

- Orbital transfer vehicle (OTV), lander, factory sizing and optimization(s).

- Observations.

- Concluding remarks. 


\section{In Situ Resource Utilization (ISRU)}

- In Situ Resource Utilization uses the materials from other places in the solar system to sustain human exploration

- Using those resources reduces the reliance on Earth launched mass, and hopefully reduces mission costs

- There are powerful capabilities to free humans from Earth 


\section{Why Atmospheric Mining?}

- Benefits:

- Large amount of matter to mine (hydrogen and helium 3)

- Potentially easier than mining regolith (dust) and rock

- Larger reservoir of materials not readily available in regolith (and in a gaseous state)

- Potential drawbacks

- Dipping deep into the gravity well of planets is expensive for propulsion systems

- Lifetime of systems

- Repetitive maneuvers

- Cryogenic atmospheric environments

- Long delivery pipelines 


\section{Uranus}

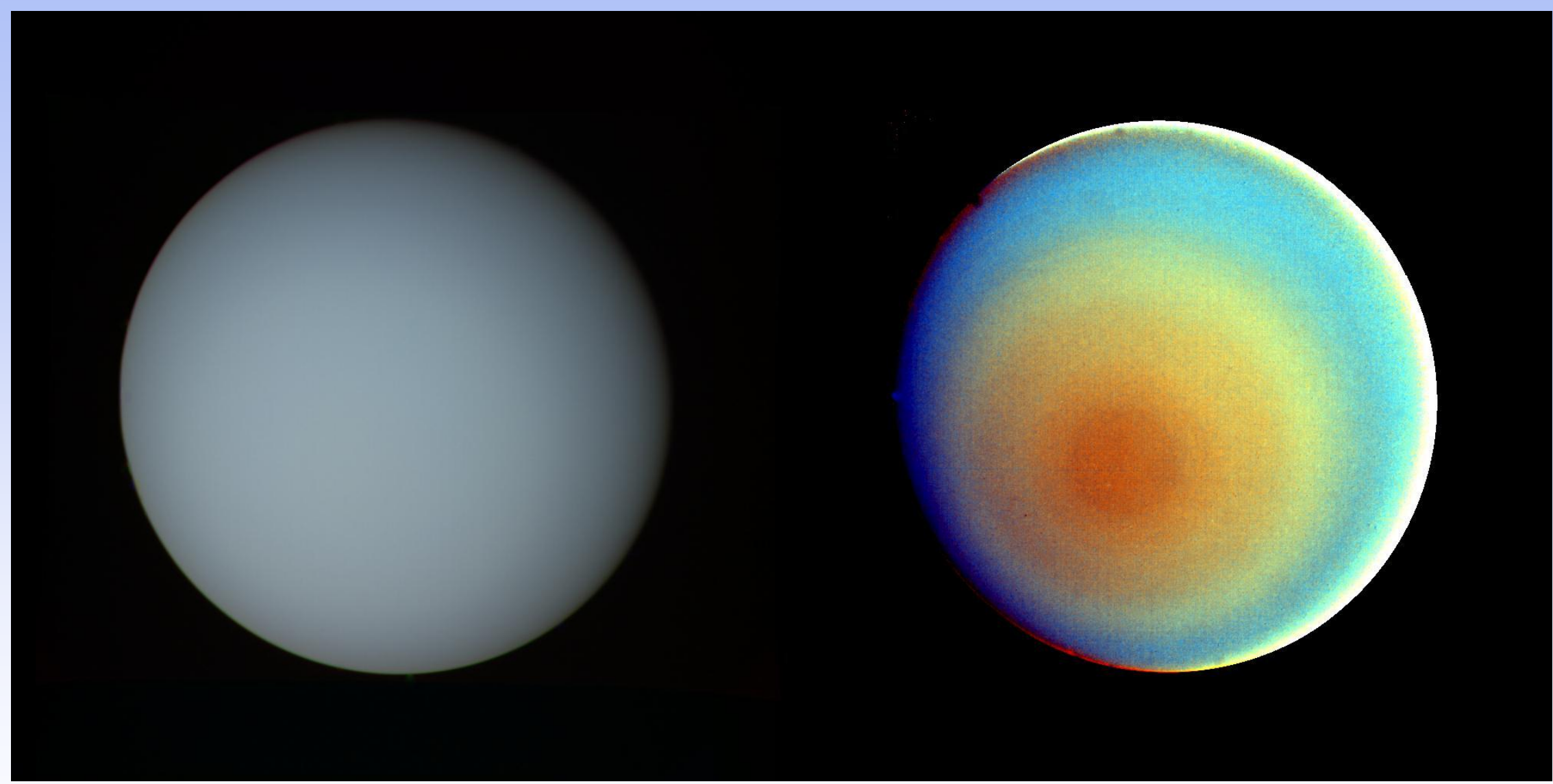

JPL 


\section{Neptune}

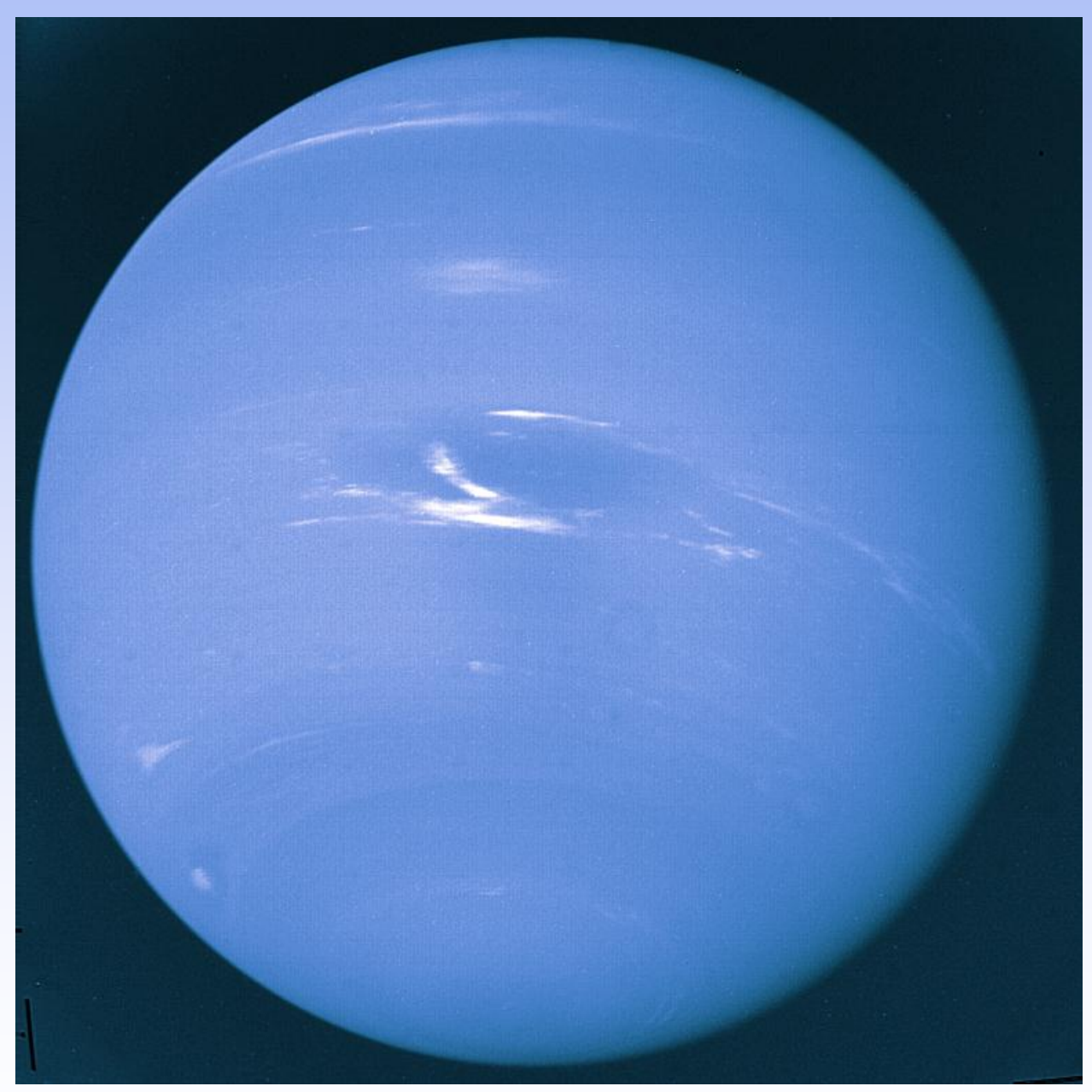

JPL 


\section{Neptune and Moons}

eptune

HST ACS/HRC

Proteus

Galatea

Despina

50,000 kilometers

Larissa

31,000 miles 


\section{Outer Planet Atmospheres}

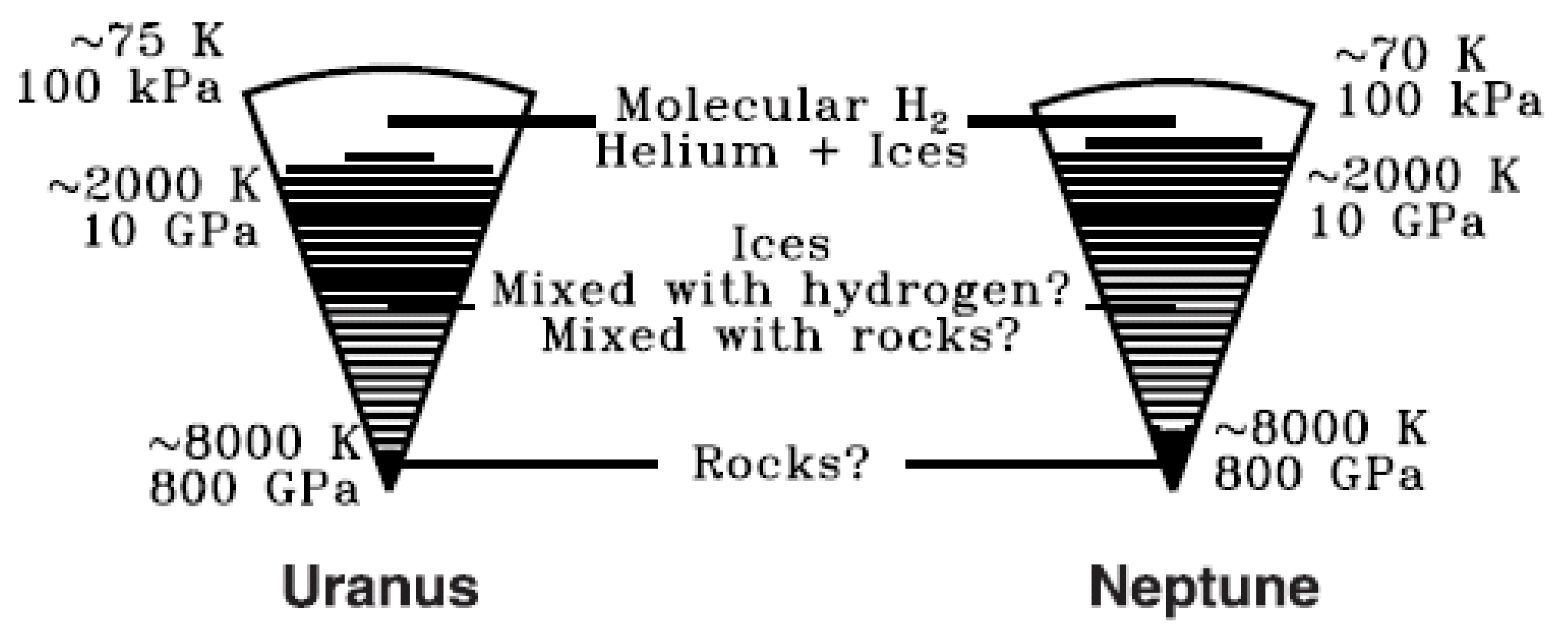

Tristan Guillot, "Interiors of Giant Planets Inside and Outside the Solar System." 


\section{Outer Planet Atmospheres and Wind Speeds}
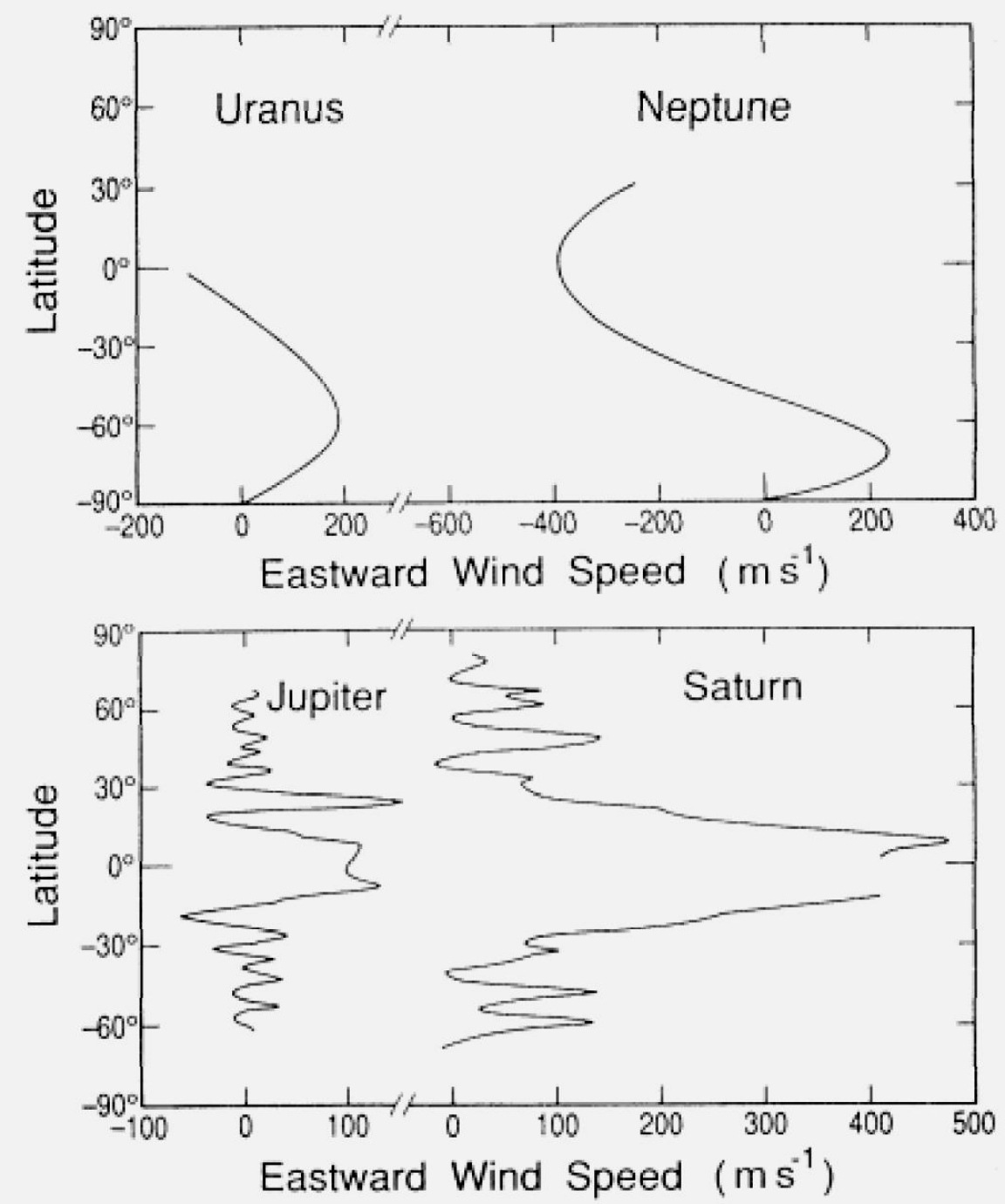

JPL, Ingersoll 


\section{Uranus - Outer Planet Atmospheres and Wind Speeds}

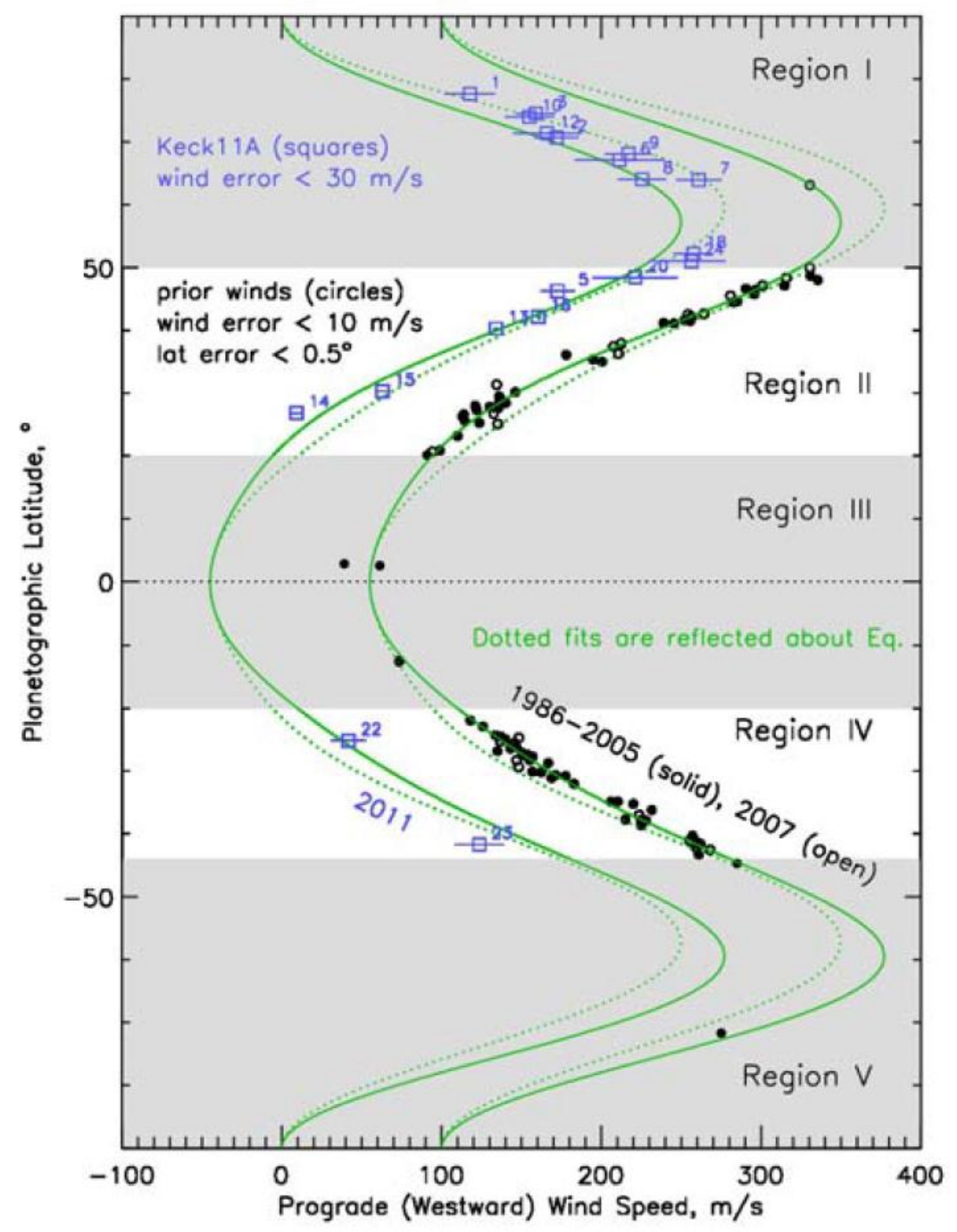

Sromovsky, L., 2010, Investigating Atmospheric Change on Uranus and Neptune, Award number NNG05GF00G. 
Uranus -

Outer Planet Atmospheres and Wind Speeds

Taken on 2011-Oct-26, at 8:33 UT L. Sromovsky and P. Fry, Univ. of Wisconsin-Madison

Sromovsky, L., 2010, Investigating Atmospheric Change on Uranus and Neptune, Award number NNG05GF00G. 


\section{ASC - UAV Selection: Weather (1/2)}

Uranus -

Outer Planet

Atmospheres

and

Wind Speeds
11 Nov 2011

\section{$H$ band}




\section{ASC - UAV Selection: Weather (2/2)}

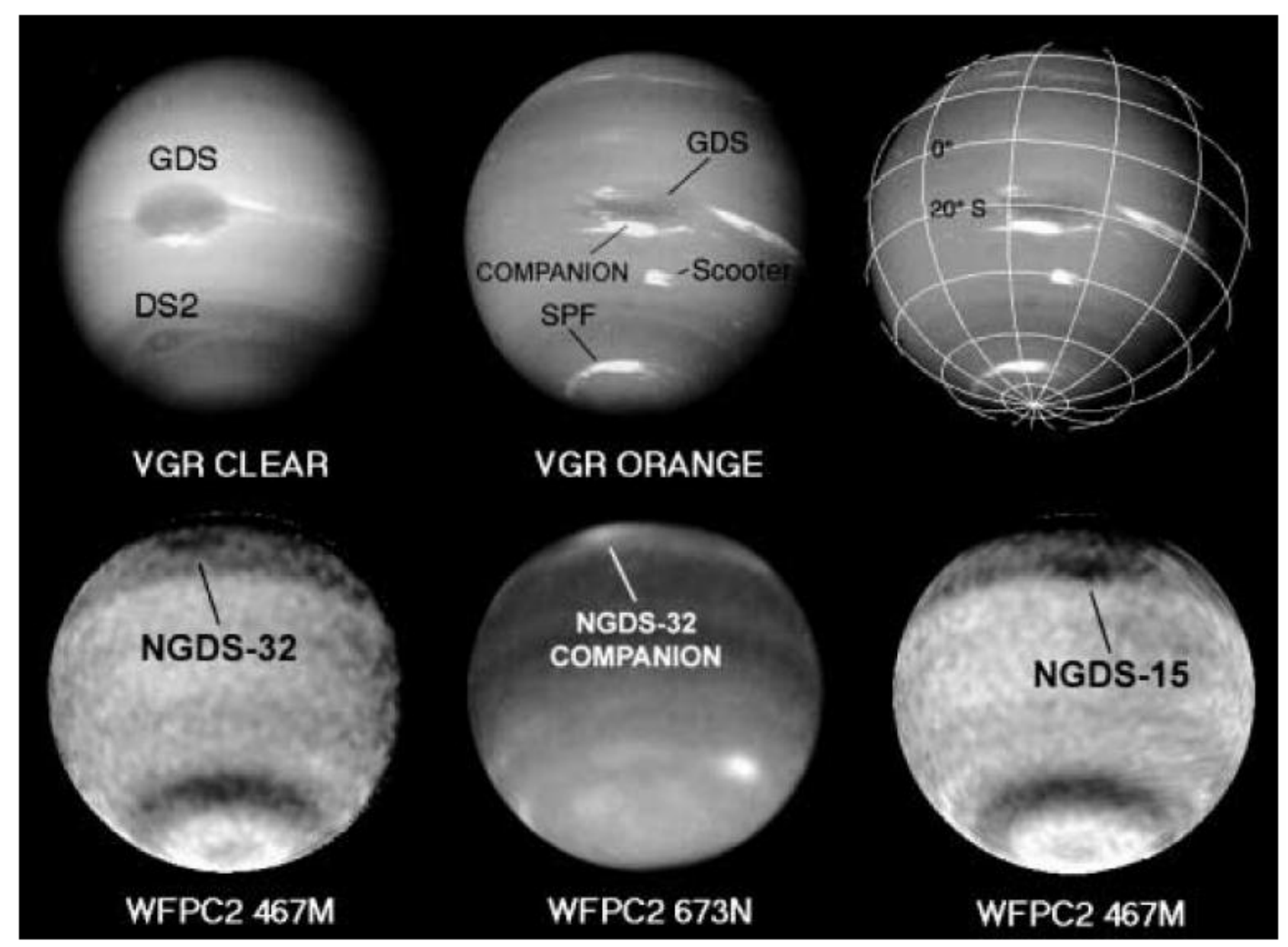

Figure B3. Neptune cloud features (Voyager, Hubble, Ref. 27) 


\section{Orbital Velocities: $10 \mathrm{~km}$ altitude}

Planet Jupiter Saturn Uranus Neptune
Delta-V (km/s) 41.897 25.492 15.053 16.618
Comment BIG BIG More acceptable More acceptable 


\section{Cruiser Mining (1) Combined Miner and Aerospacecraft}

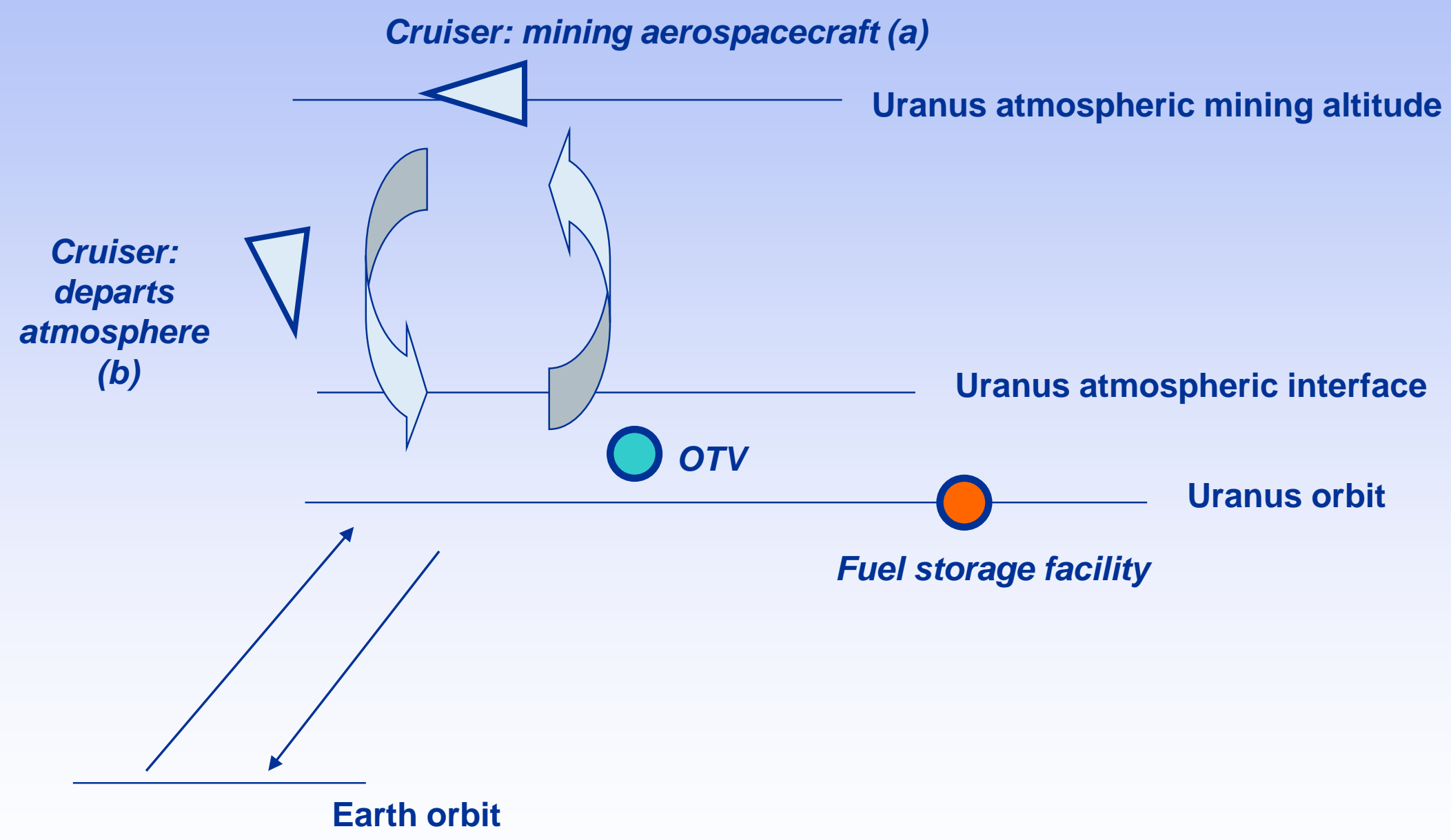




\section{Mining Scenarios and OTVs}

- Using cruiser aerospacecraft for mining in the atmosphere at subsonic speeds.

- Cruiser aerospacecraft then ascends to orbit, transferring propellant payload to orbital transfer vehicles (OTV).

- OTV will be the link to interplanetary transfer vehicle (ITV) for return to Earth.

- Moon bases for a propellant payload storage option was investigated. 


\section{AMOSS GCR Designs}

\section{CLOSED-CYCLE GAS CORE NUCLEAR ROCKET}

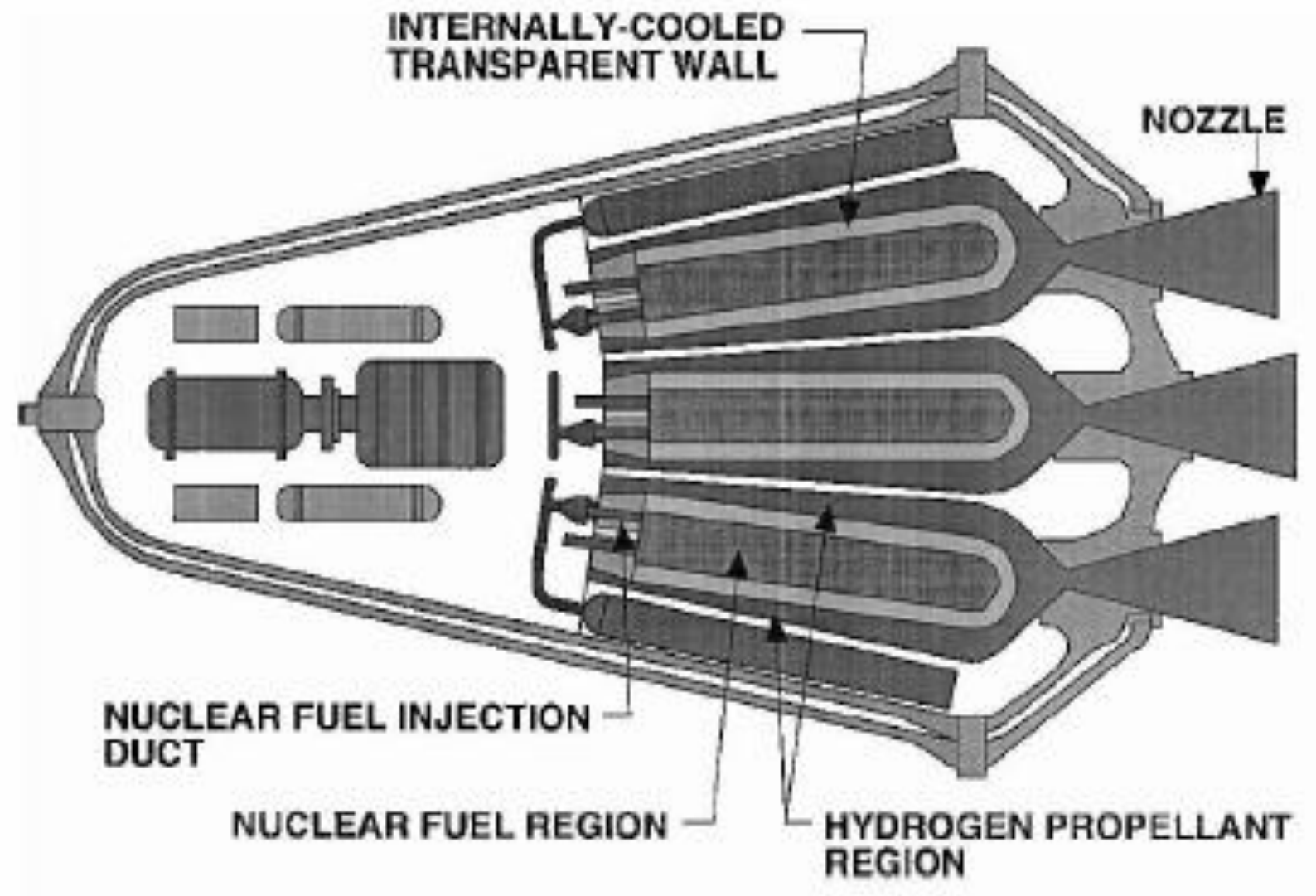




\section{Gas Core Design and Analysis Overview}

- Total aerospacecraft vehicle delta-V is $20 \mathrm{~km} / \mathrm{s}$.

- Single stage aerospacecraft.

- Gas core Isp values = 1800 and 2500 seconds

- Vehicles mass estimated over a broad range of dry masses.

- Dry mass (other than tankage) $=1,000,10,000$, 100,000 , and $1,000,000 \mathrm{~kg}$.

- Typical gas core dry mass $=80,000$ to $200,000 \mathrm{~kg}$.

- Tankage mass $=2 \%$ and $10 \%$ of propellant mass.

- Comparative case: solid core NTP Isp $=900$ seconds. 


\section{Gas core, Isp $=1,800 s$, Tankage $=2 \% M p$}

Nuclear Aerospacecraft,

OC Gas Core; 1,800-s Isp; 20-km/s delta-V capability;

1,000-kg payload

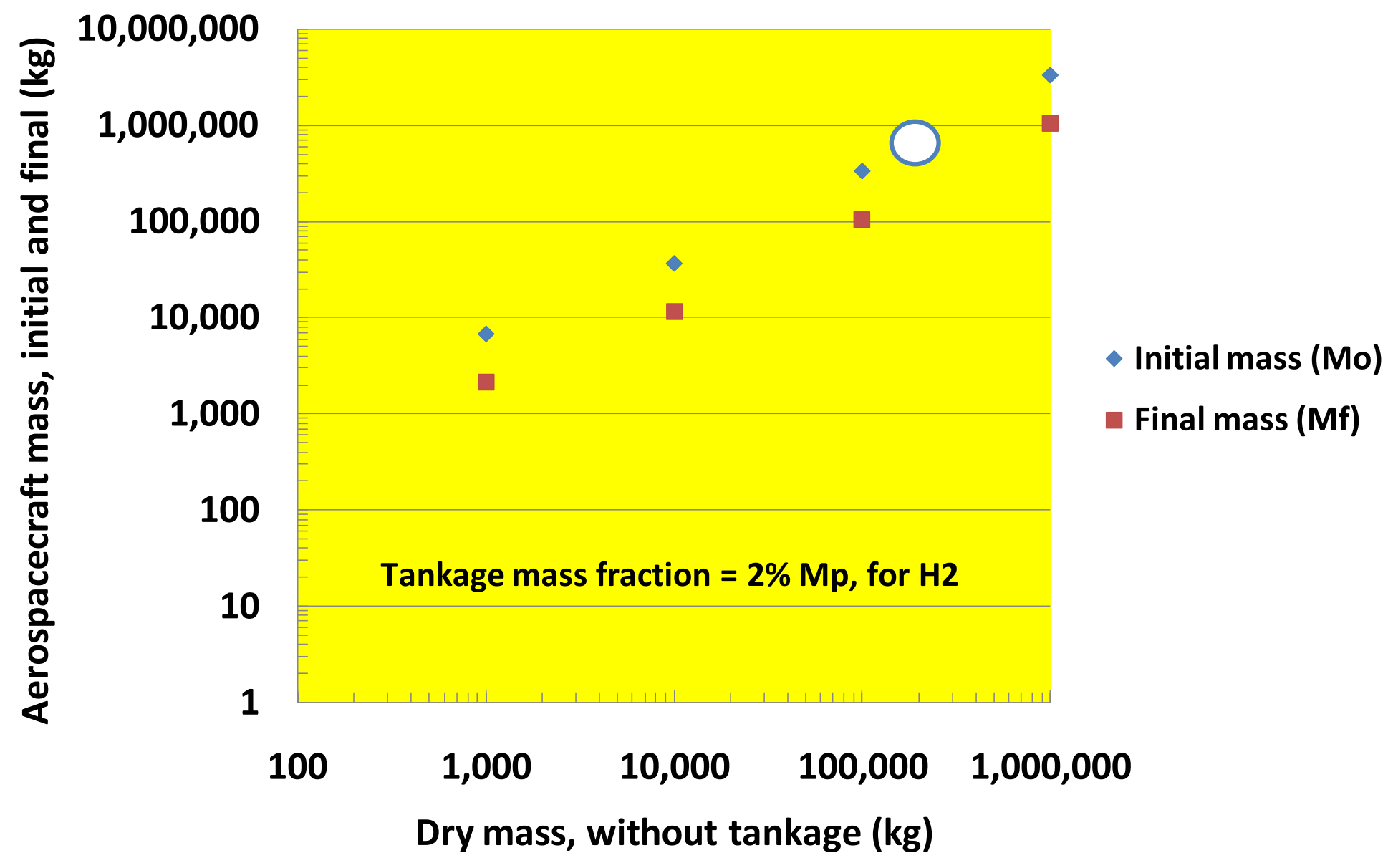




\section{AMOSS NTP Designs: Solid Core and Gas Core}

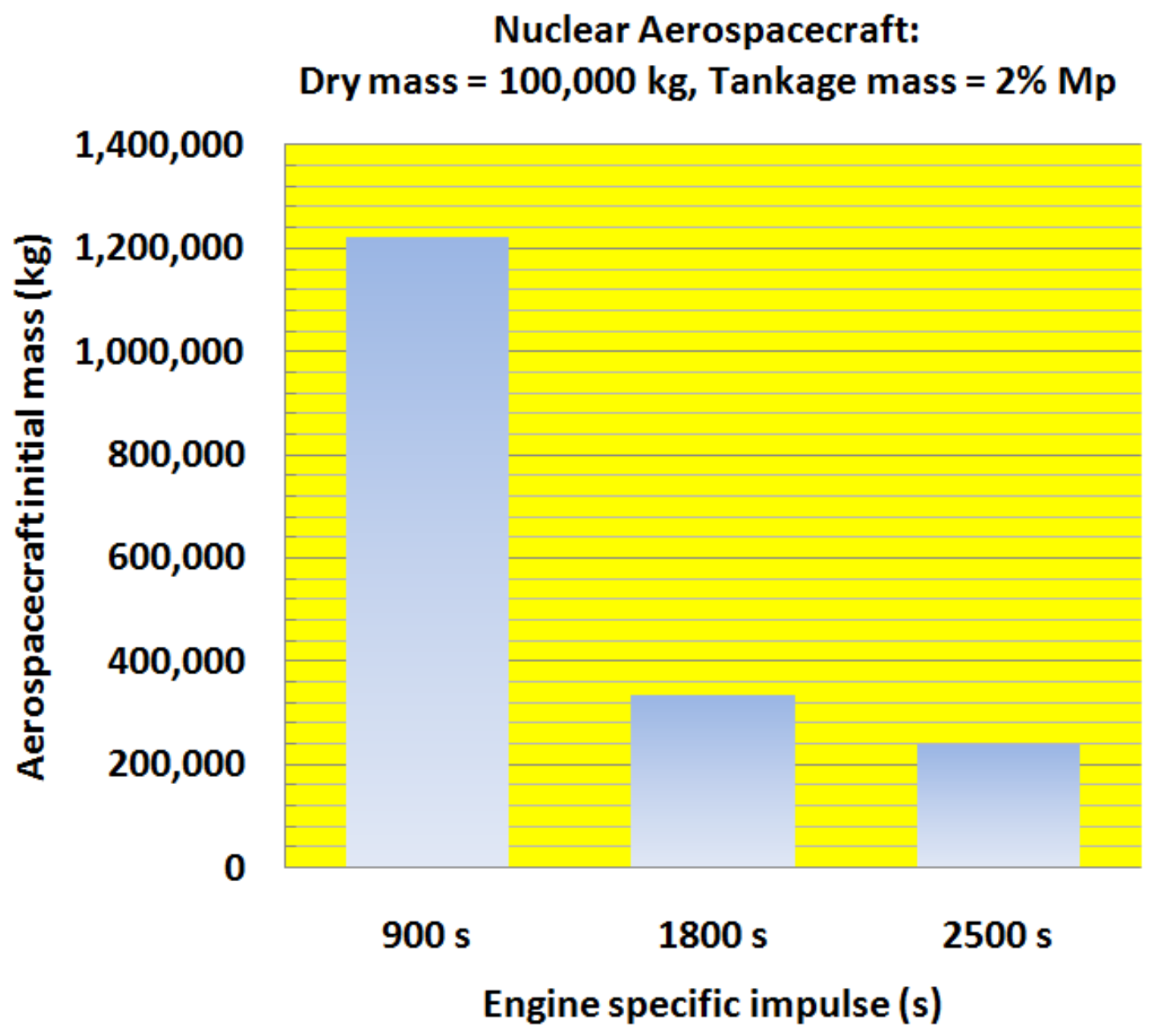




\section{Time for $3 \mathrm{He}$ Capture at Uranus}

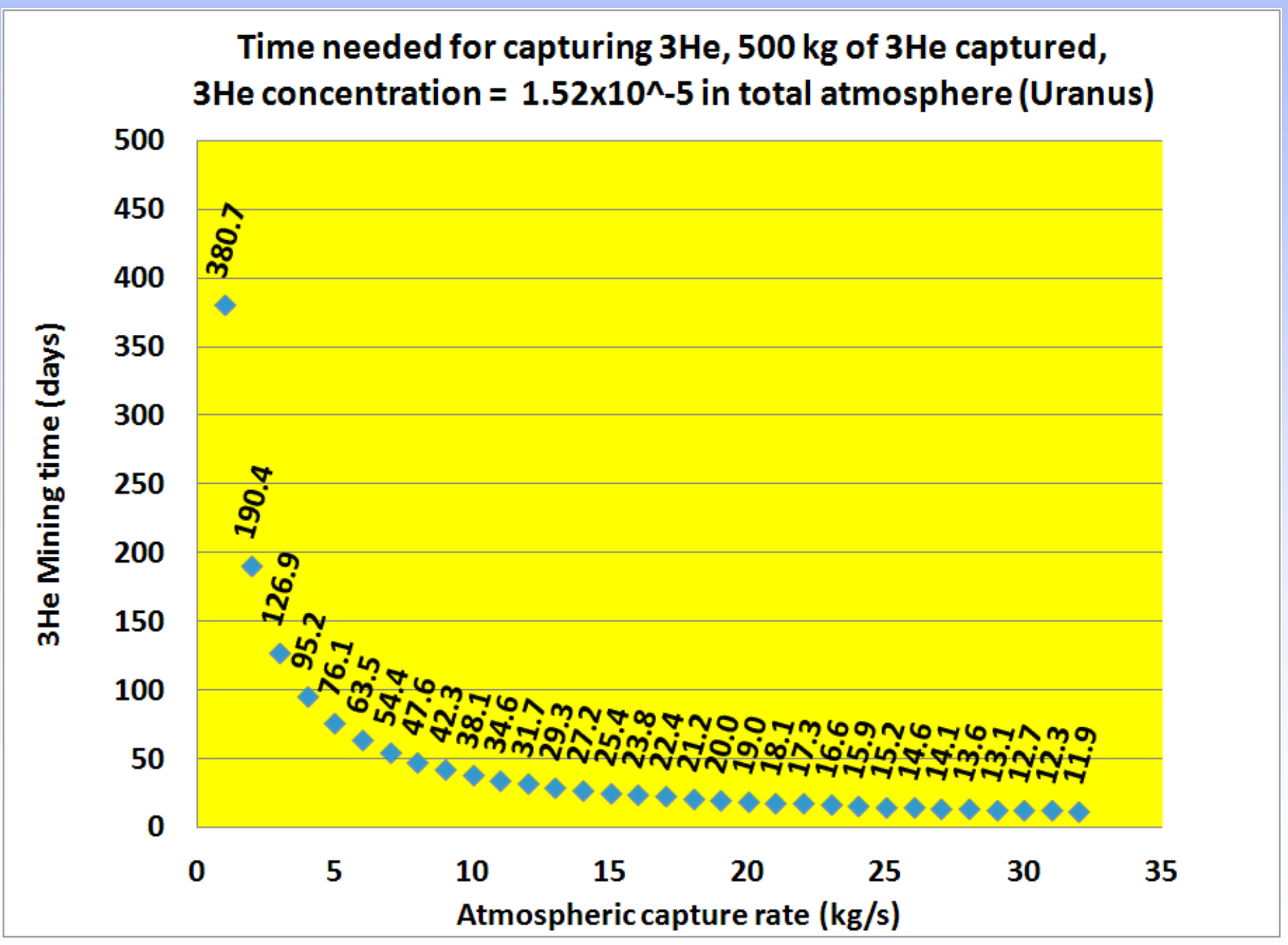




\section{Time for $3 \mathrm{He}$ Capture at Neptune}

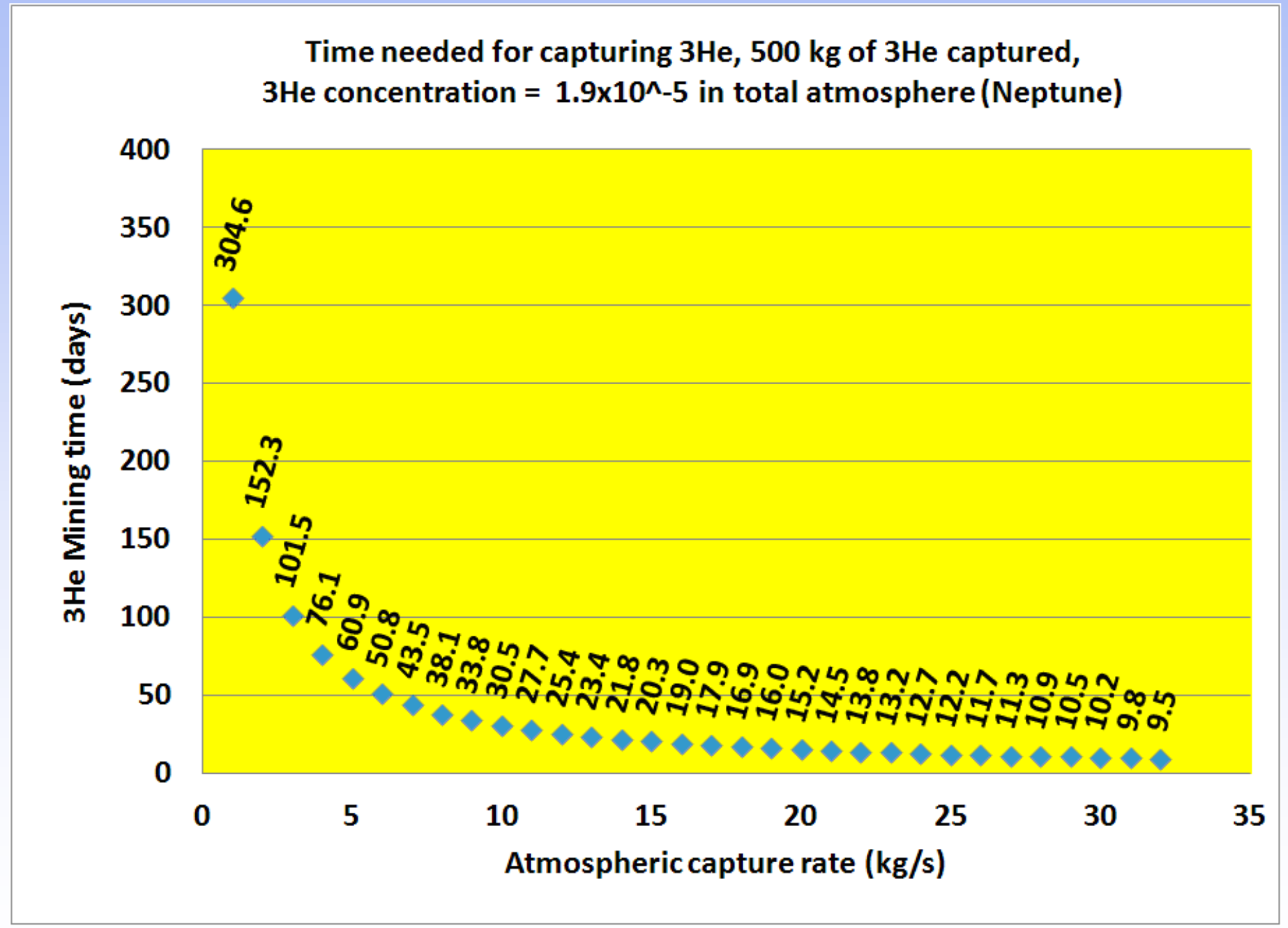




\section{Resource Capturing - Hydrogen, Helium 4, and Helium 3 Comparison, Uranus}

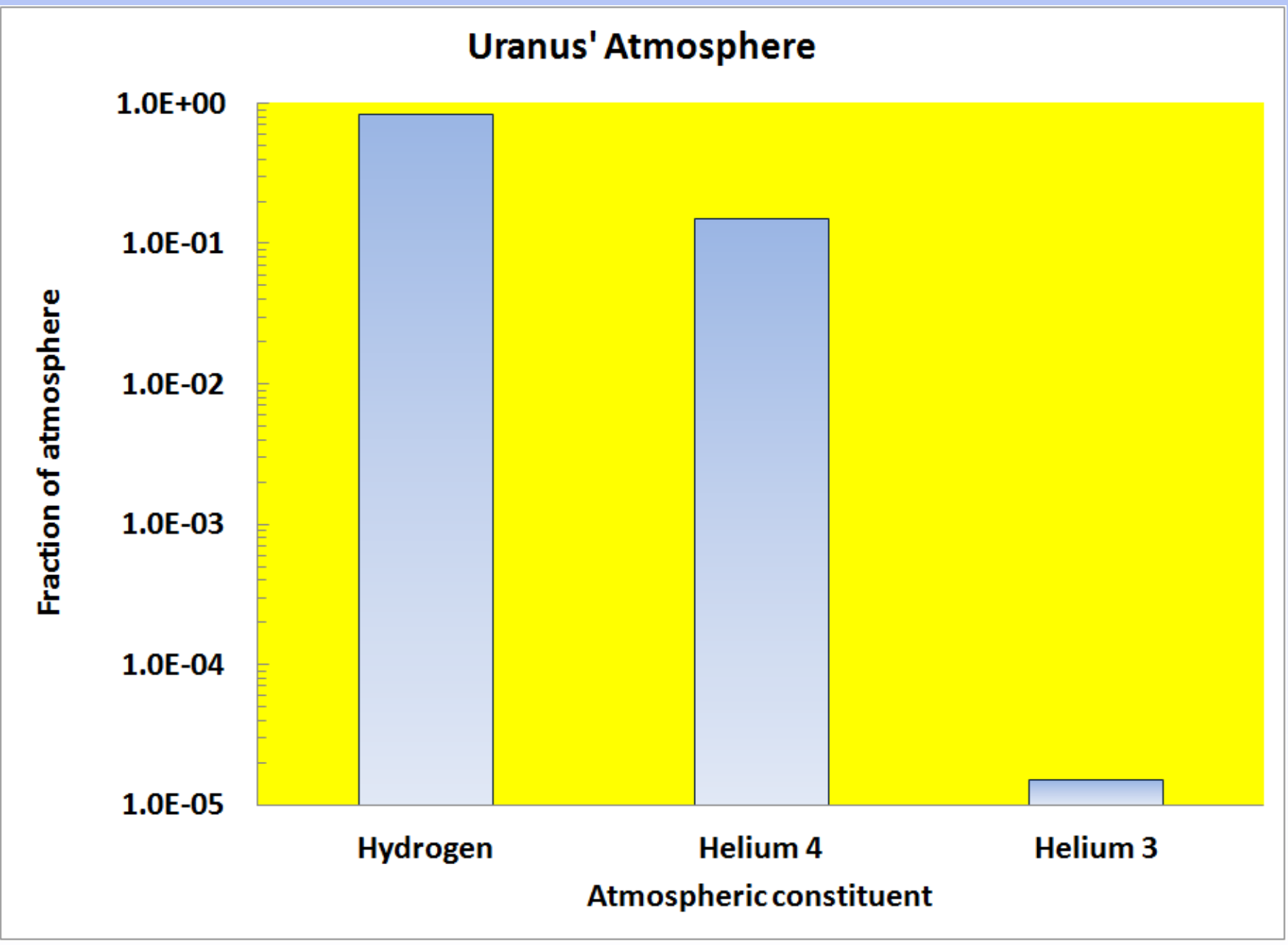




\section{AMOSS, Hydrogen Production at Uranus}

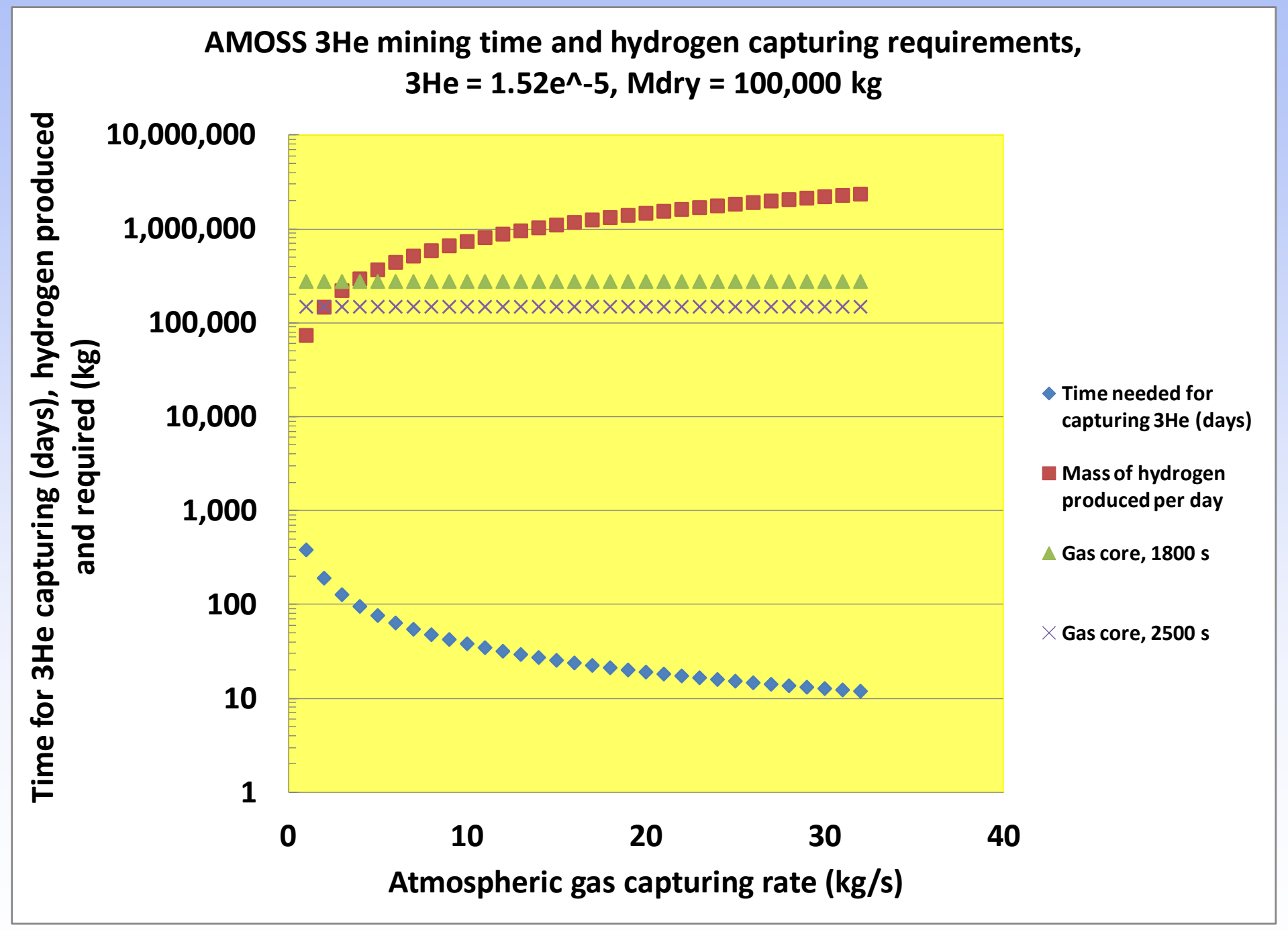


Aerospacecraft (ASC) as an Observational

Unmanned Aerial Vehicle (UAV) (1/2)

- In the 2014 AMOSS studies, a series of UAVs for data gathering near atmospheric phenomena was suggested.

- While the UAV idea is attractive, the size of many of the storms may make data gathering in the atmosphere an arduous task.

- Orbital monitoring, as with Earth observing satellite may be the key.

- If very long term in-situ operations are needed with a UAV, perhaps the mining ASC would be the best solution. 
Aerospacecraft (ASC) as an Observational

Unmanned Aerial Vehicle (UAV) (2/2)

- The ASC has a longer range and the lifetime of its gas core reactor may exceed the solid core reactors.

- The 2014 results implied a reactor lifetime of approximately 30 hours (Refs.1 and 21 ).

- Circumnavigating the large planetary storms may require much longer periods of time

- Uranus and Neptune "geostationary" satellites could provide the needed global weather data and other visual observations.

- After determining the most important science target(s), the ASC derived UAV would do the more detailed measurements, having the ability to loiter in the storm area. 
AMOSS Transportation Infrastructure and Implications - Uranus System

- Aerospacecraft (ASC) enter atmosphere and begins mining

- Lander(s) place the ISRU factories on Titania.

- ISRU factory begins oxygen and hydrogen production.

- Lander is fueled with ISRU oxygen and hydrogen.

- Lander is loaded with hydrogen payload for OTV.

- OTV and lander rendezvous, OTV is fueled for round trip mission to Saturn.

- OTV picks up helium 3 from ASC.

- OTV delivers helium 3 to Lander (in Titania orbit).

- Lander refuels OTV and delivers helium 3 to ISRU factory (PPack). 


\section{OTV Design and Masses (Initial Mass)}

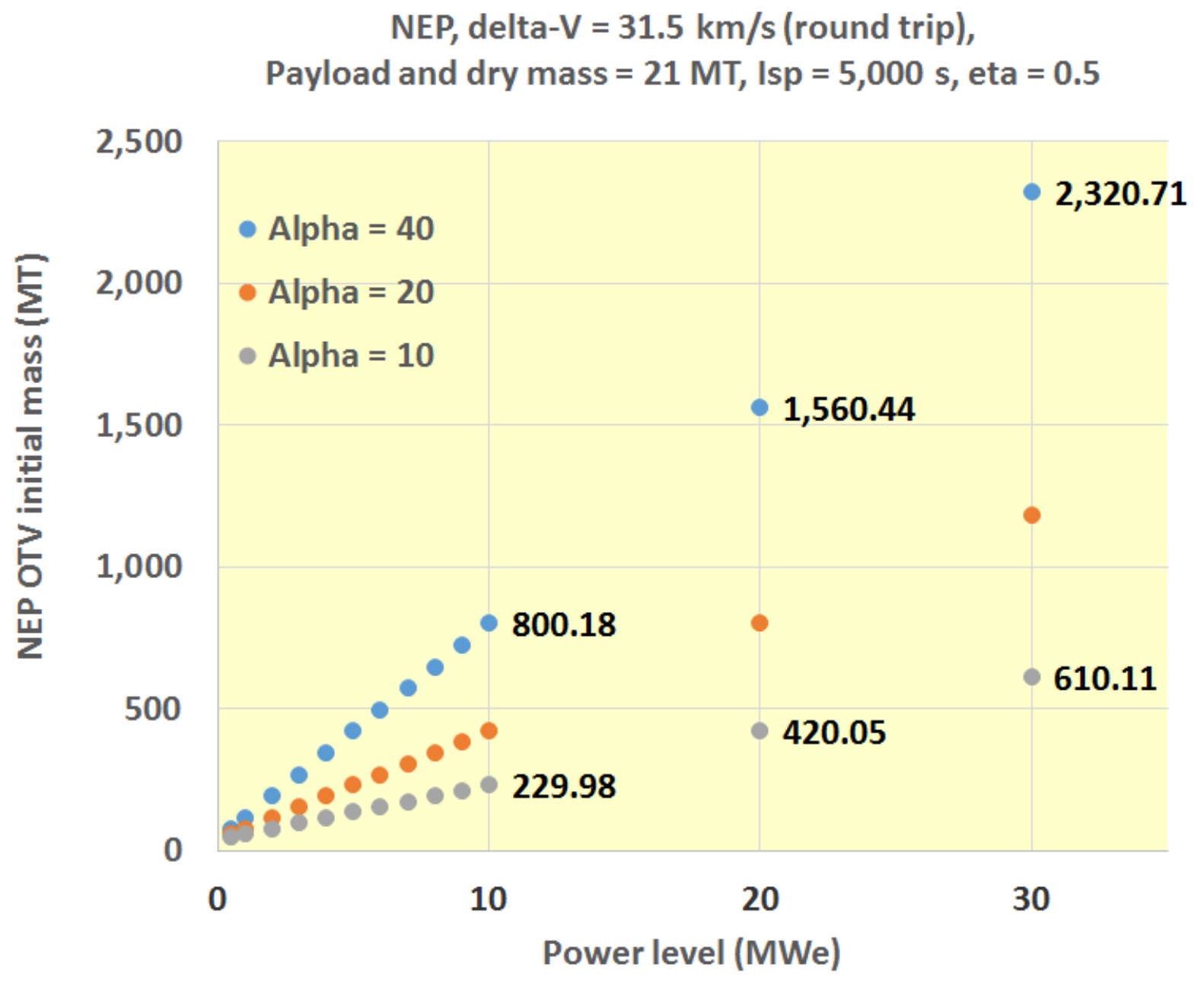




\section{OTV Design and Masses (Propellant Mass)}

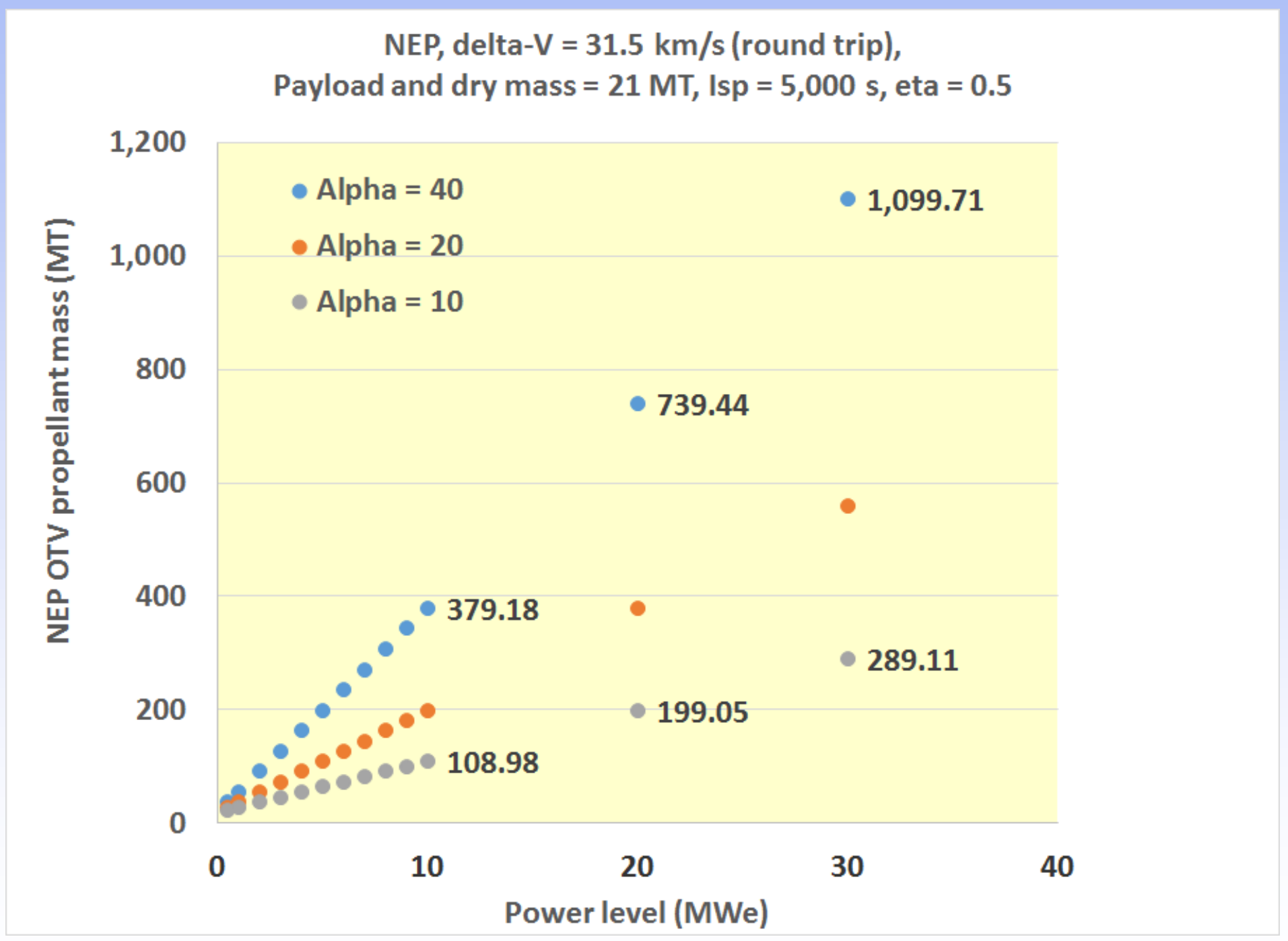




\section{OTV Design and Masses (Trip Time)}

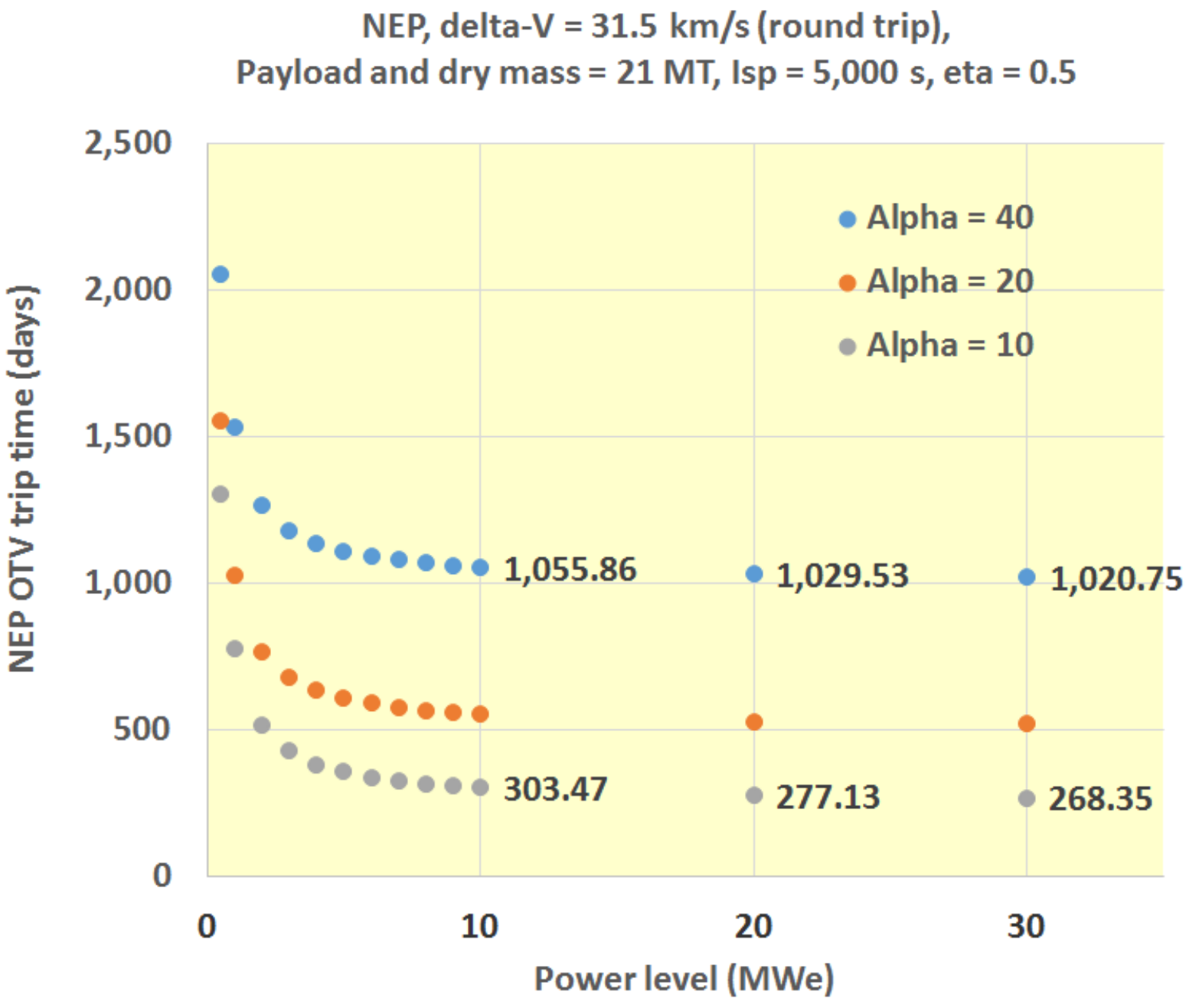




\section{OTV Design and Masses (Lander Payloads)}

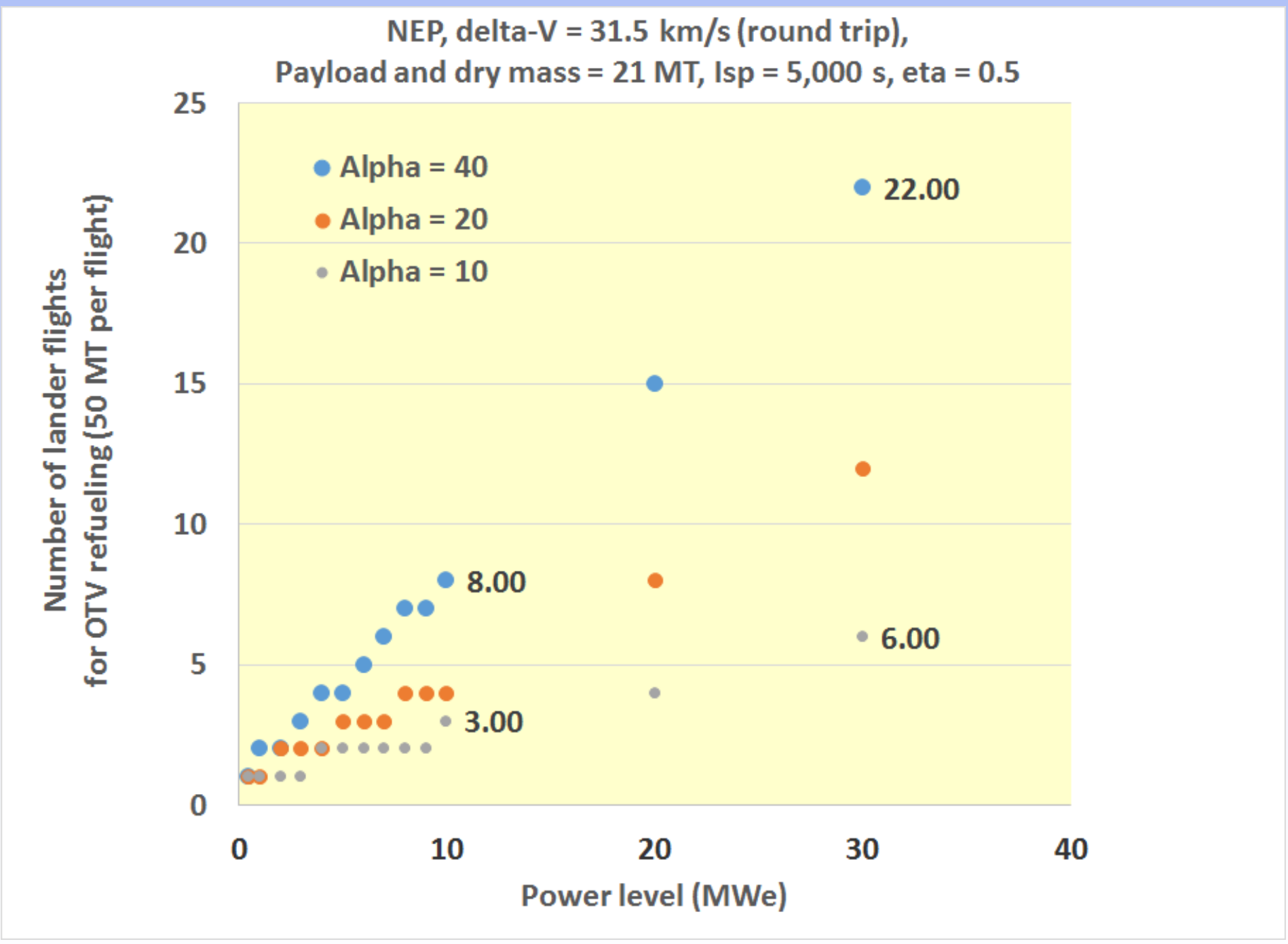




\section{OTV Design and Masses (Lander Payloads)}

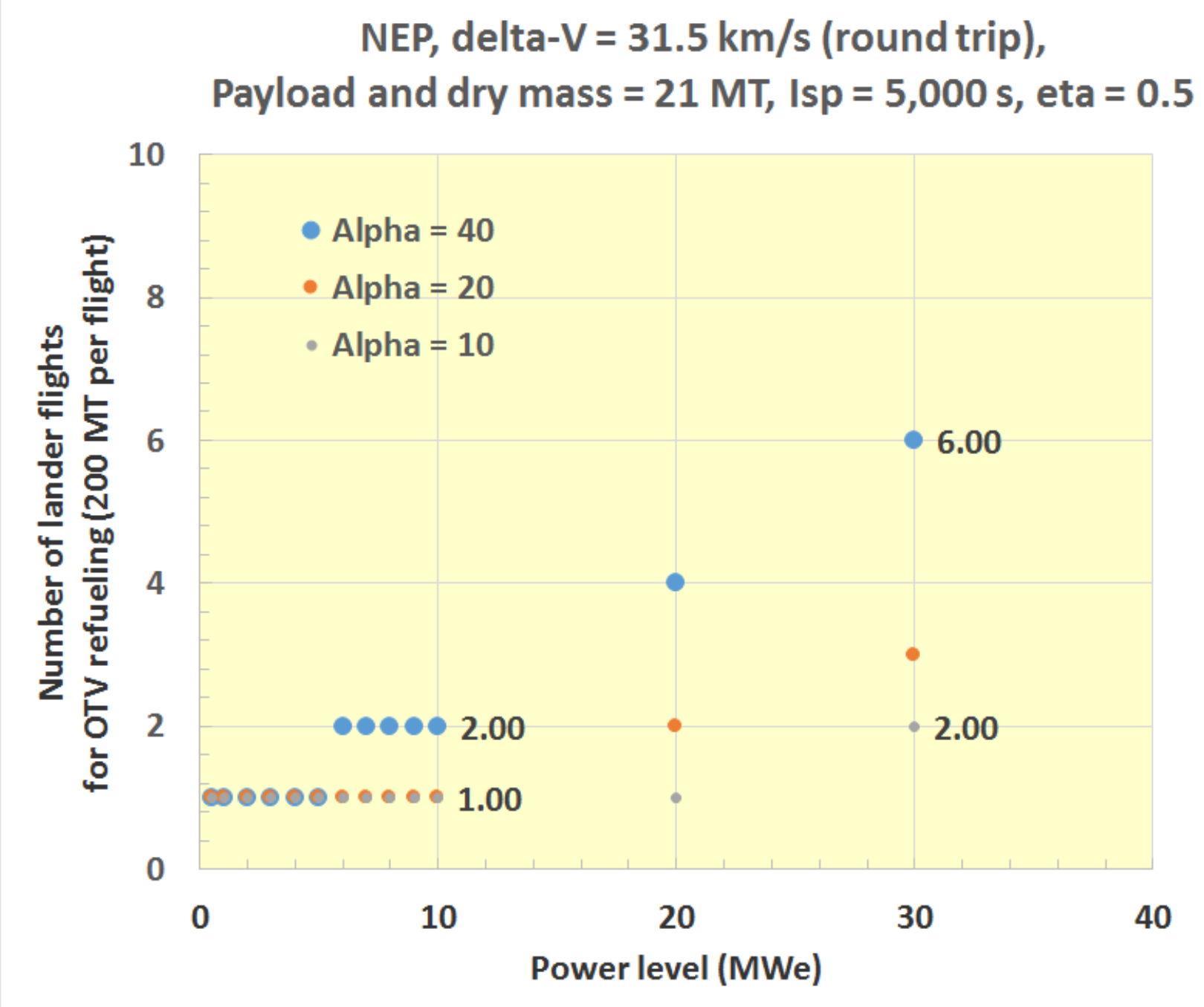




\section{Lander Design and Masses}

- The lander's mission is to deliver hydrogen to the OTV and return to the moon with the helium 3 or deuterium payload(s).

- The round trip delta-V would be $0.8 \times 2$ or $1.60 \mathrm{~km} / \mathrm{s}$.

- This $0.8 \mathrm{~km} / \mathrm{s}$ delta-V value represents the energy to reach escape conditions from the moon Titania.

- Thus, the lander has the capability to reach escape conditions to rendezvous with the OTV.

- The lander was designed with an oxygen hydrogen main propulsion system.

- The lander Isp was varied from 400 to $\mathbf{4 8 0}$ seconds. The dry mass scaling equation was:

- Mdry, stage $(\mathbf{k g})=$ Mdry, coefficient $\bullet$ Mp (kg)

- Mdry, coefficient $=0.2$ and 0.4 
ISRU Factory Design and Masses

- The masses of the propellant factories were based on four design options:

- Lightweight factory (all external storage and processing),

- Heavy factory (also with external storage and processing),

- Lightweight factory with propellants fed to the lander,

- Super lightweight factory, using integral propellant storage on the lander (with no external lander propellant or fluid storage).

- The range of masses were from 7 MT for the super lightweight case (using integral propellant storage on the lander) to $21 \mathrm{MT}$ for the heavy factory. 
Preliminary Transportation Optimization (1/4)

- Establishing an optimum transportation system will be influenced by many factors: the OTV mass and power level, the payload mass of the lander and the selection of the moon for the mining factories.

- Several optima will be created based on the size and mass of the moon selected.

- The moon's mass will strongly influence the propellant mass needed for the refueling of its oxygen/hydrogen propulsion system and the time needed for creating the fuel for the OTV. 
Preliminary Transportation Optimization (2/4)

- With the OTVs, the 10 MWe power level appears to be the most acceptable.

- The initial mass of the OTV with power levels of 20 and $30 \mathrm{MWe}$ is too high, with no significant trip time benefits over the OTV at the 10 MWe power level.

- For the $21 \mathrm{MT}$ dry mass case, at $10 \mathrm{~kg} / \mathrm{kWe}$, and at 5,000 seconds of Isp, the trip time for the $30 \mathrm{MWe}$ level is 269 days versus $\mathbf{3 0 4}$ days at the 10 MWe level.

- With the $40 \mathrm{~kg} / \mathrm{kWe}$ case (with the same Isp and dry mass), the trip time at $30 \mathrm{MWe}$ is 1,021 versus 1,056 for the 10 MWe case. 
Preliminary Transportation Optimization (3/4)

- The OTV trip times are a significant issue.

- Many flight times are 100's of days.

- Initially, a single 1 MT payload of helium 3 or deuterium would fly on each OTV flight.

- Multiple helium 3 or deuterium payloads will have to be manifested on the OTVs.

- While the OTV and the lander can rendezvous at the moon's escape conditions, it may be more stable to conduct the propellant and payload transfers at a high moon orbit, but not at or beyond the moon's escape conditions. 
Preliminary Transportation Optimization (4/4)

- Lander payloads of 200 MT provide the minimal number of lander flights.

- The processing on the moon of the propellant, the propellant loading, and the cryogenic hydrogen payload loading may favor the largest payload capacity lander.

- With the 200 MT hydrogen payload, the number of lander flights needed to refuel the 21 MT dry mass $(5,000$ seconds Isp) OTV is 1 flight for the $10 \mathrm{~kg} / \mathrm{kWe}$ case and 2 flights for the $40 \mathrm{~kg} / \mathrm{kWe}$ case.

- Landers might be further optimized by increasing their payload capacity, which would further reduce the number of flights. 


\section{Concluding Remarks (1/2)}

- Using outer planet moon bases for mining propellants for OTVs and landers is an important option.

- Storing the AMOSS nuclear fuels away from the atmosphere will minimize the potential for unanticipated deorbiting of the orbiting storage facility.

- Using the moons for storage of the nuclear fuels and base of operations for OTV refueling is an excellent option.

- Though the gravity of these moons are much lower than that of Earth, that gravity will likely assist in any processes for mining and fuel processing. 


\section{Concluding Remarks (2/2)}

- The 10 MWe power levels for the OTV seems best for providing a relatively short trip time.

- The OTVs and landers will rendezvous near the escape condition of the small moon, shortening the trip time for the OTV (eliminating the need to spiral into low moon orbit).

- Larger landers (of 200 MT payloads) are more attractive than small landers, as the large landers require fewer flights to resupply the OTVs with fuel.

- The OTV trip times may be too long for effective use of the more distant moons. Moons that are closer to the planet may be required. 
Neptune, Go ISRU

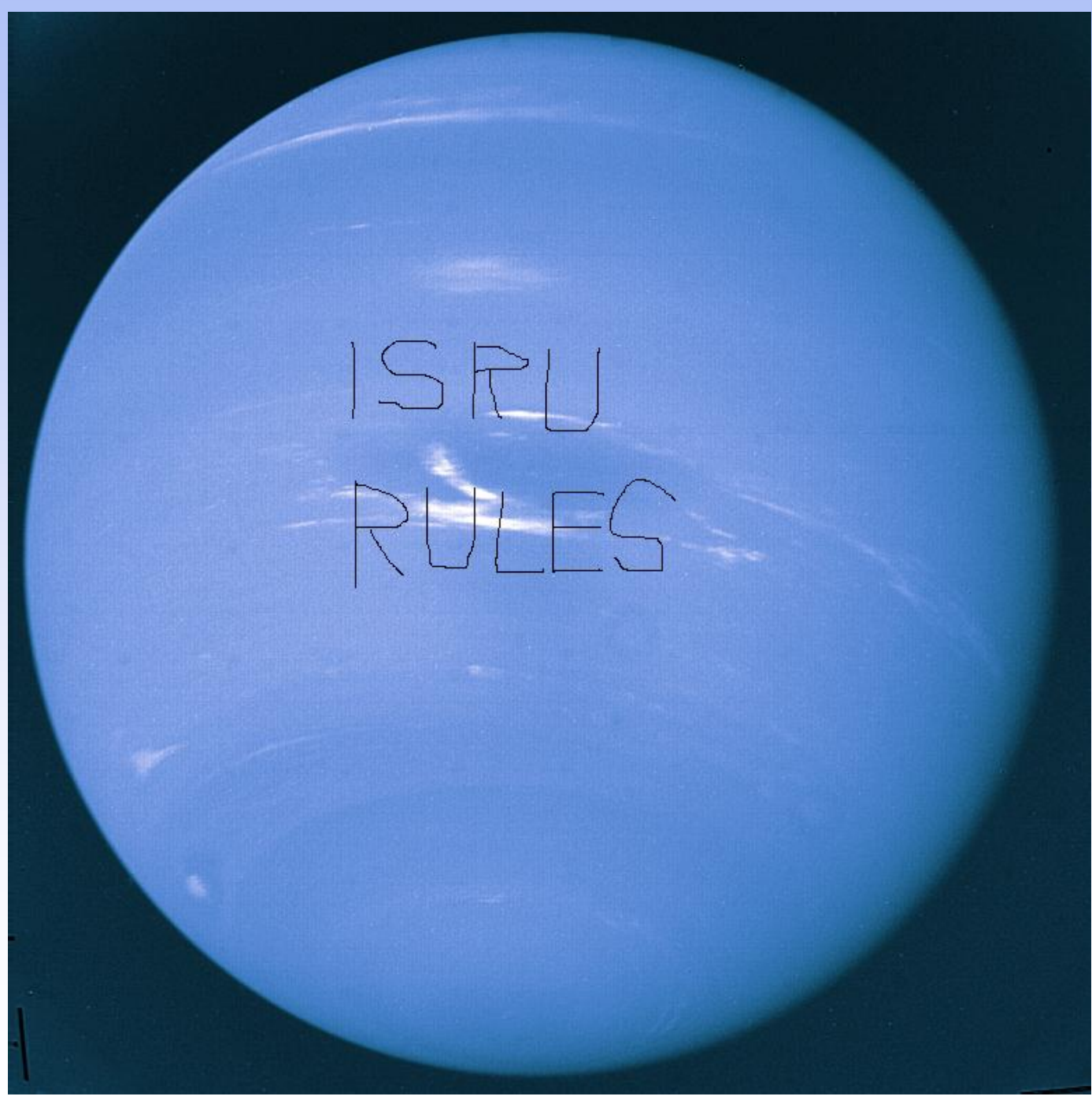




\section{ADAY OKA JUPIER'S MOON LST LESS THAN 5 HOURS}

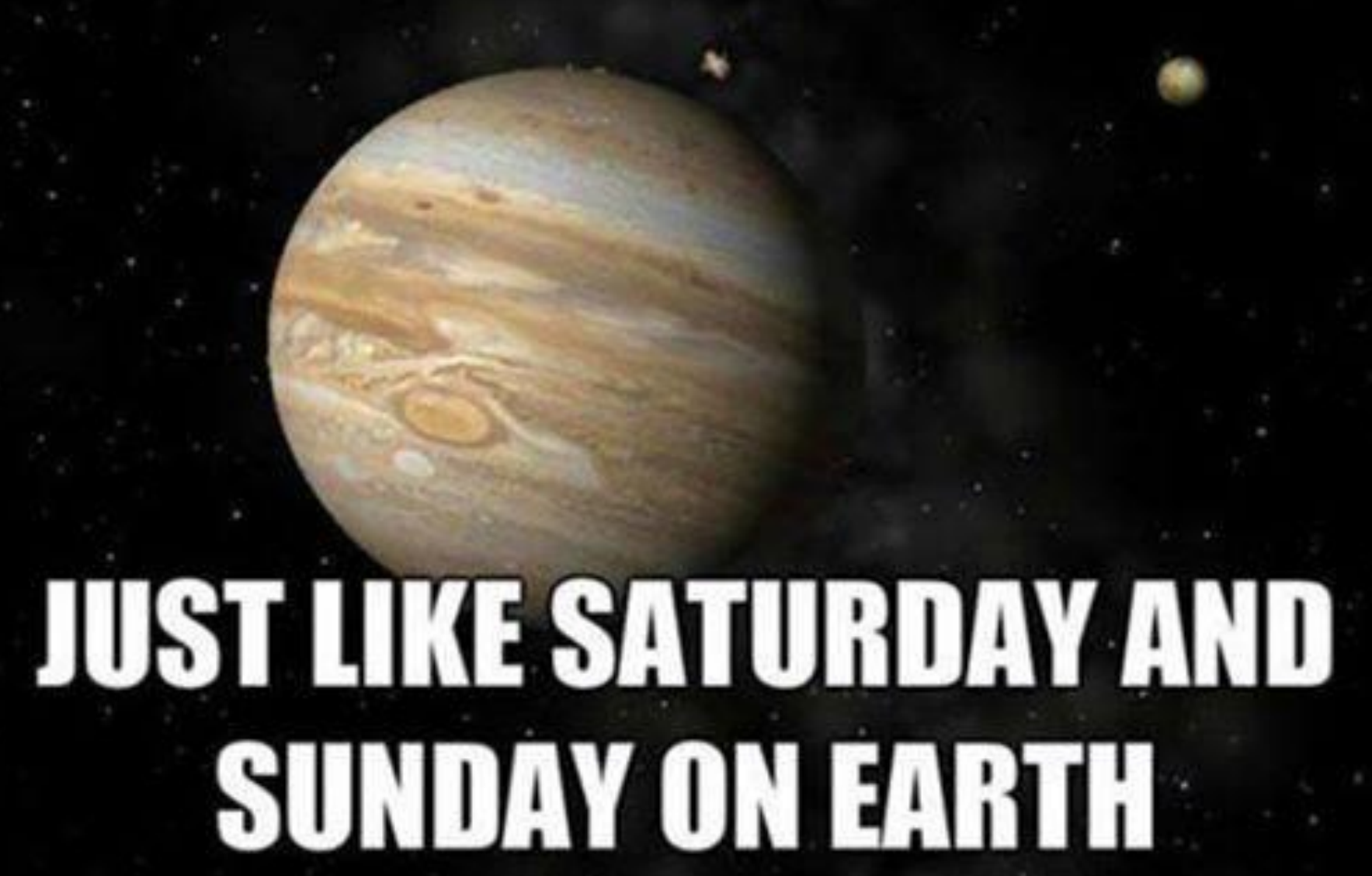




\section{AMOSS Constellation \\ Atmospheric Exploration Missions (1/2)}

- AMOSS helium 3 (3He) mining produces large amounts of additional hydrogen and helium.

- Given the fact that large amounts of hydrogen and helium are available, new missions can be conceived for vehicles in the outer planet atmosphere(s).

- Fleets of such aerospacecraft (ASC) vehicles could be fueled with AMOSS produced hydrogen and helium. 


\section{AMOSS Constellation Atmospheric Exploration Missions (2/2)}

- Potential missions include:

- Aircraft for weather data gathering, weather warnings.

- Deep diving subsonic "aircraft" probes that can go to low altitudes with 10X, 20X, 30X atmospheric pressures (a la scoopers).

- Launching of GPS-ish vehicles to improve mining (ASC) communications.

- Delivery of samples to orbital assets. 


\section{Exploration UAV size ranges}

Probe design

Free fall

Parachute

Rocket boost

Rocket return

Long duration, subsonic

Aerospacecraft (mining)
Mass (MT)

1 to 10

1 to 10

10 to 100

10 to 1,000

10 to 1,000

100 to 10,000 


\section{UAV Configurations: High Speed (4a/4)}

\section{Nuclear Ramjet Flyer}

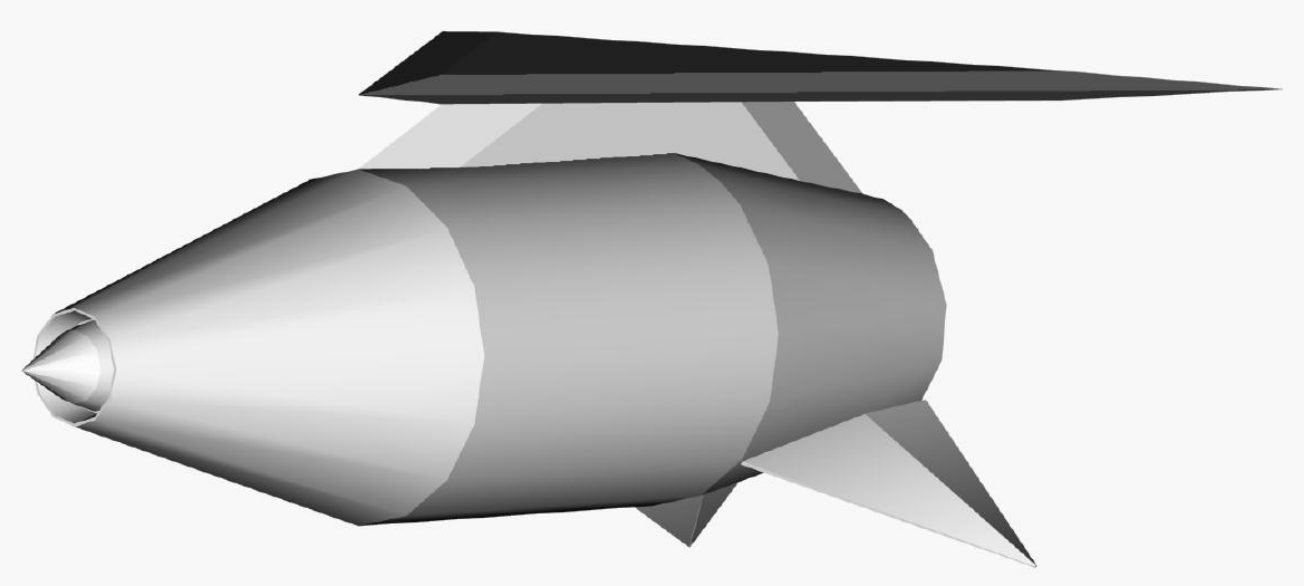




\section{UAV Configurations: High Speed (4b/4)}
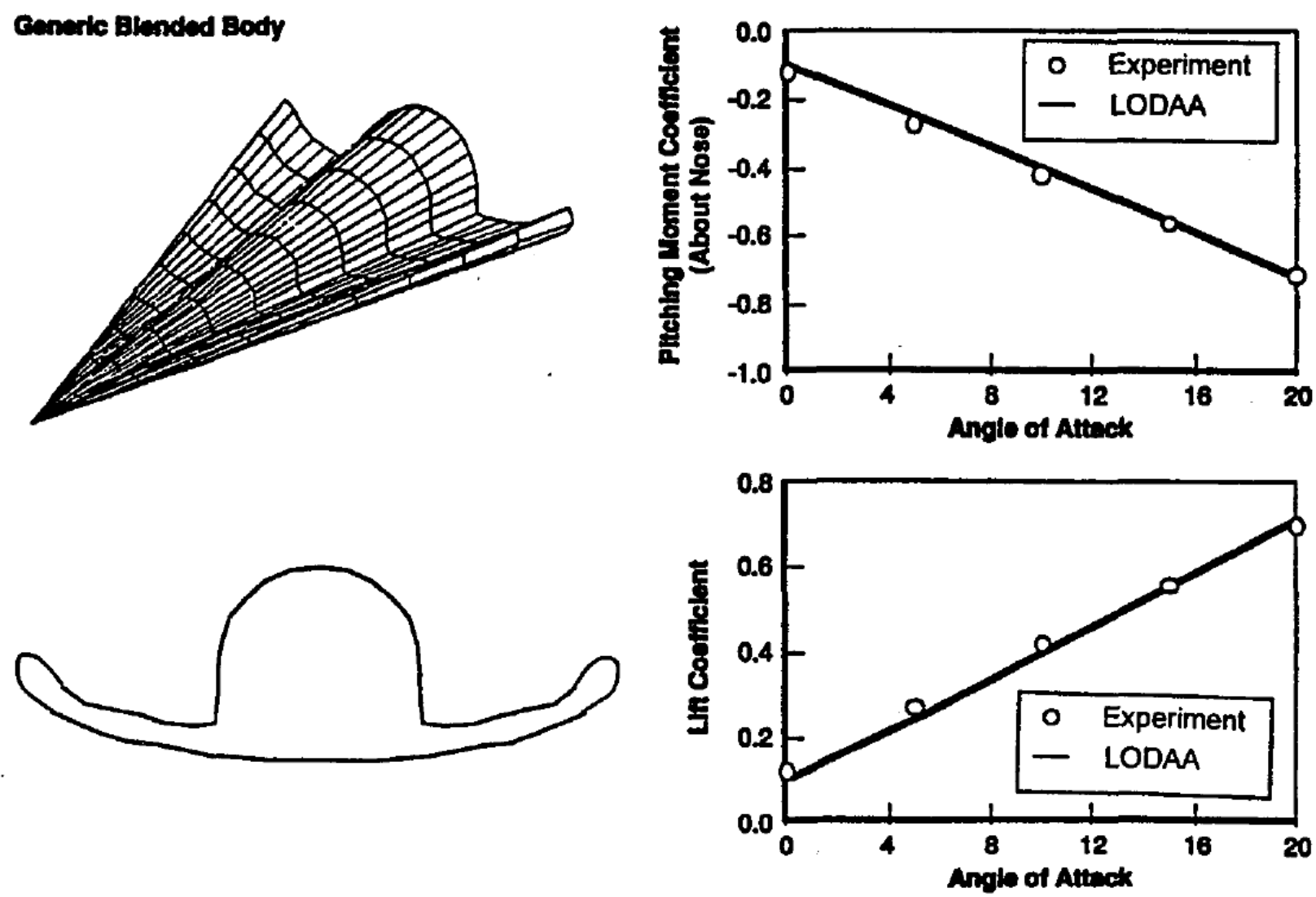

Nuclear Ramjet Flyer

Figure 8. LODAA Predictions for a Blended Body Shape 


\section{UAV Configurations: High Speed (4c/4)}

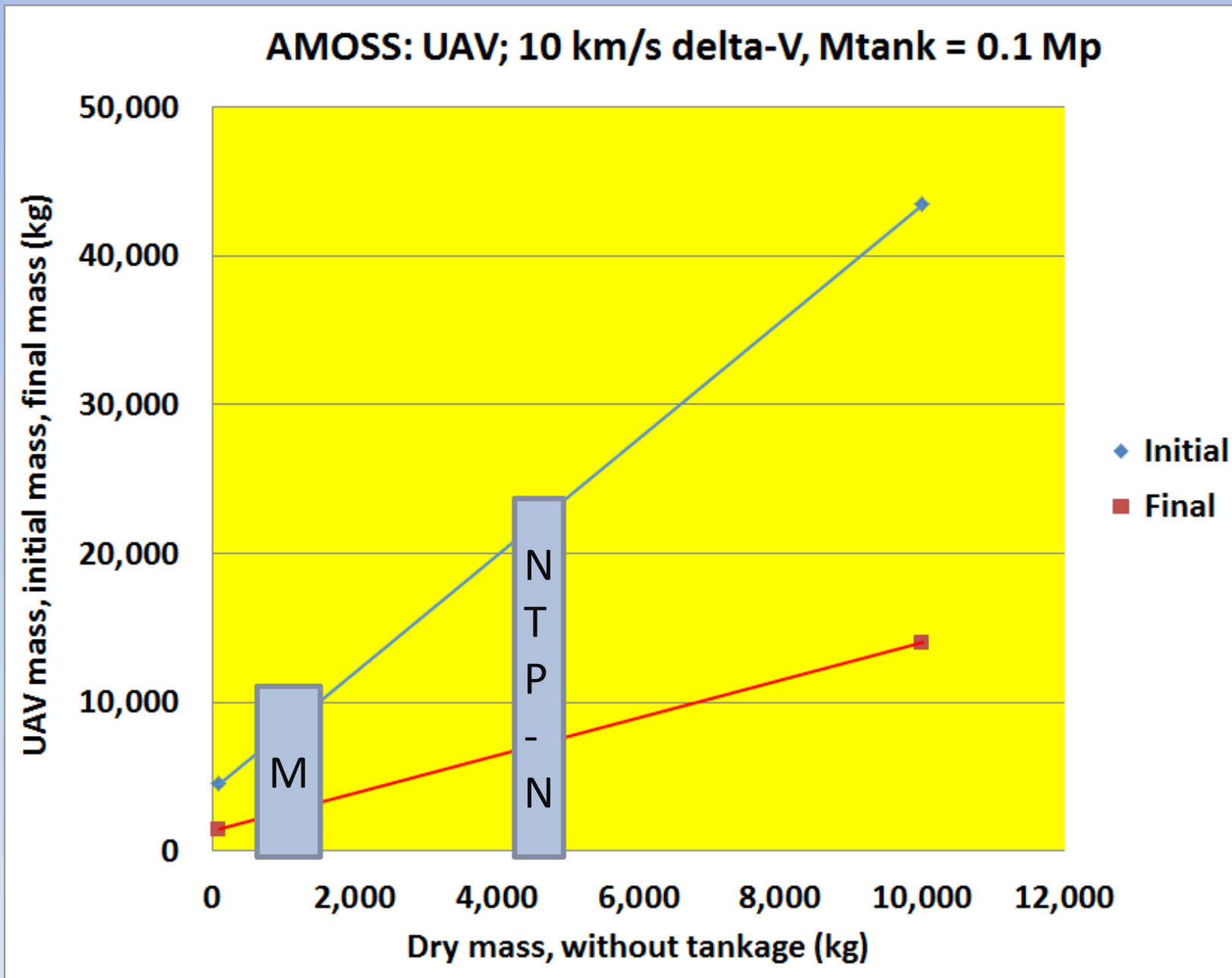

Nuclear Ramjet Flyer

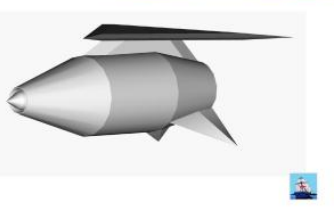


Uranus -

Outer Planet Atmospheres and Wind Speeds

Taken on 2011-Oct-26, at 8:33 UT L. Sromovsky and P. Fry, Univ. of Wisconsin-Madison

Sromovsky, L., 2010, Investigating Atmospheric Change on Uranus and Neptune, Award number NNG05GF00G. 


\section{UAV Mission Planning: Weather Phenomena, Uranus}

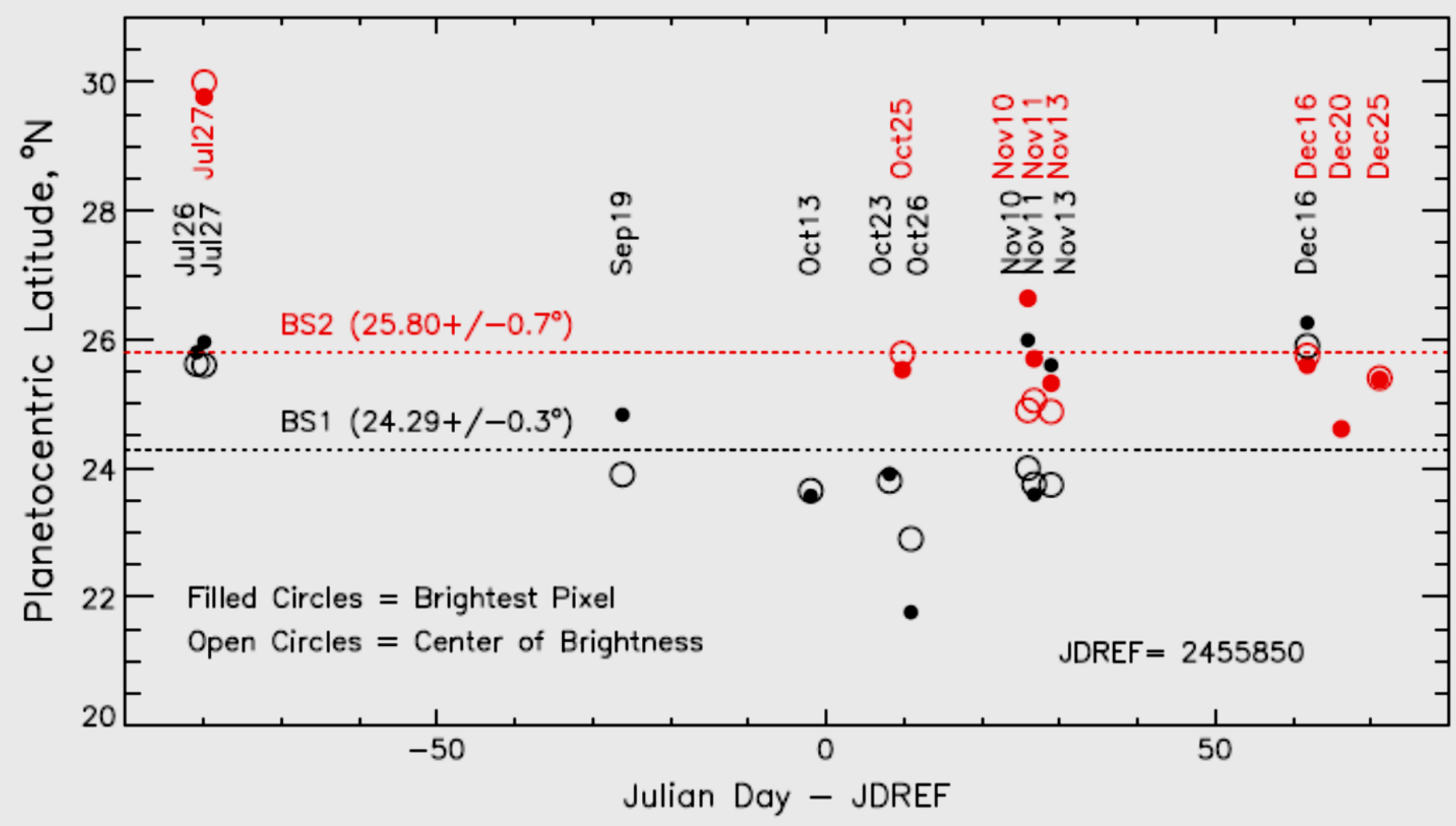

Uranus atmospheric phenomena (Reference 24) 


\section{UAV Mission Planning: Aurora Phenomena, Uranus}

F. Herbert, B.R. Sandel / Planetary and Space Science 47 (1999) 1119-1139

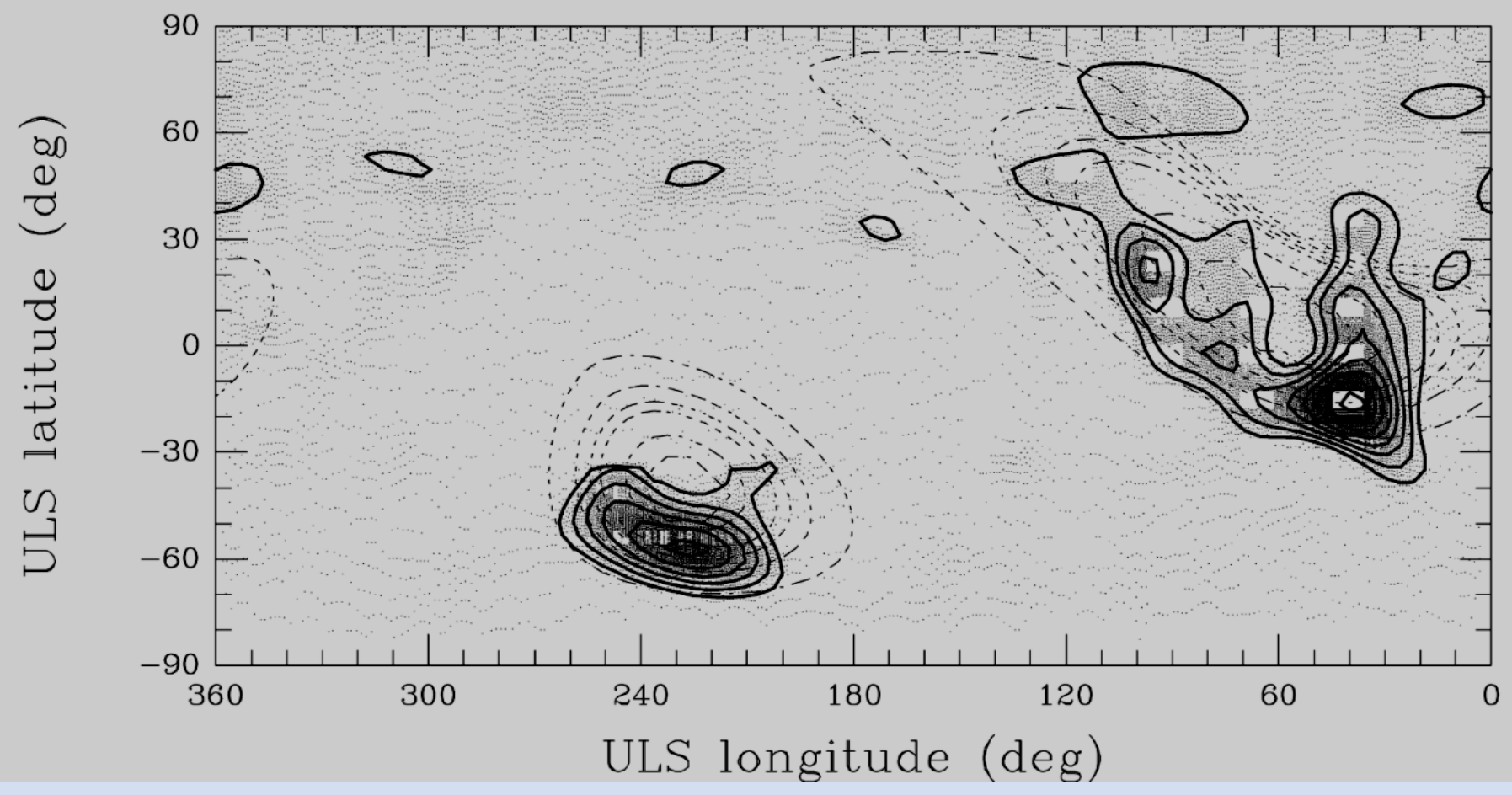

Uranus atmospheric phenomena (Reference 23) 


\section{UAV Configurations: Weather (3a/4)}

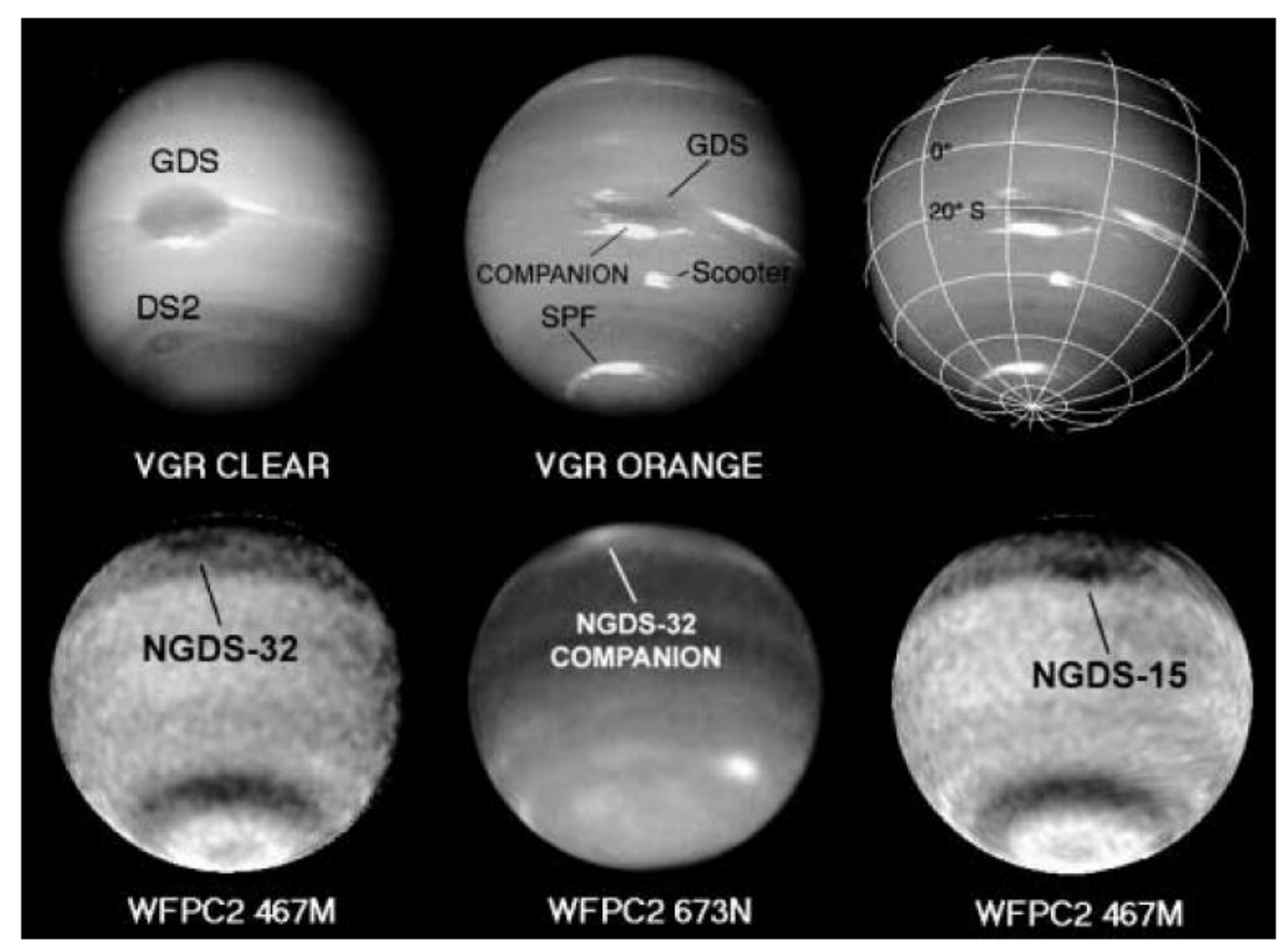

Figure B3. Neptune cloud features (Voyager, Hubble, Ref. 27) 


\section{UAV Mission Planning: Weather Phenomena: Neptune}

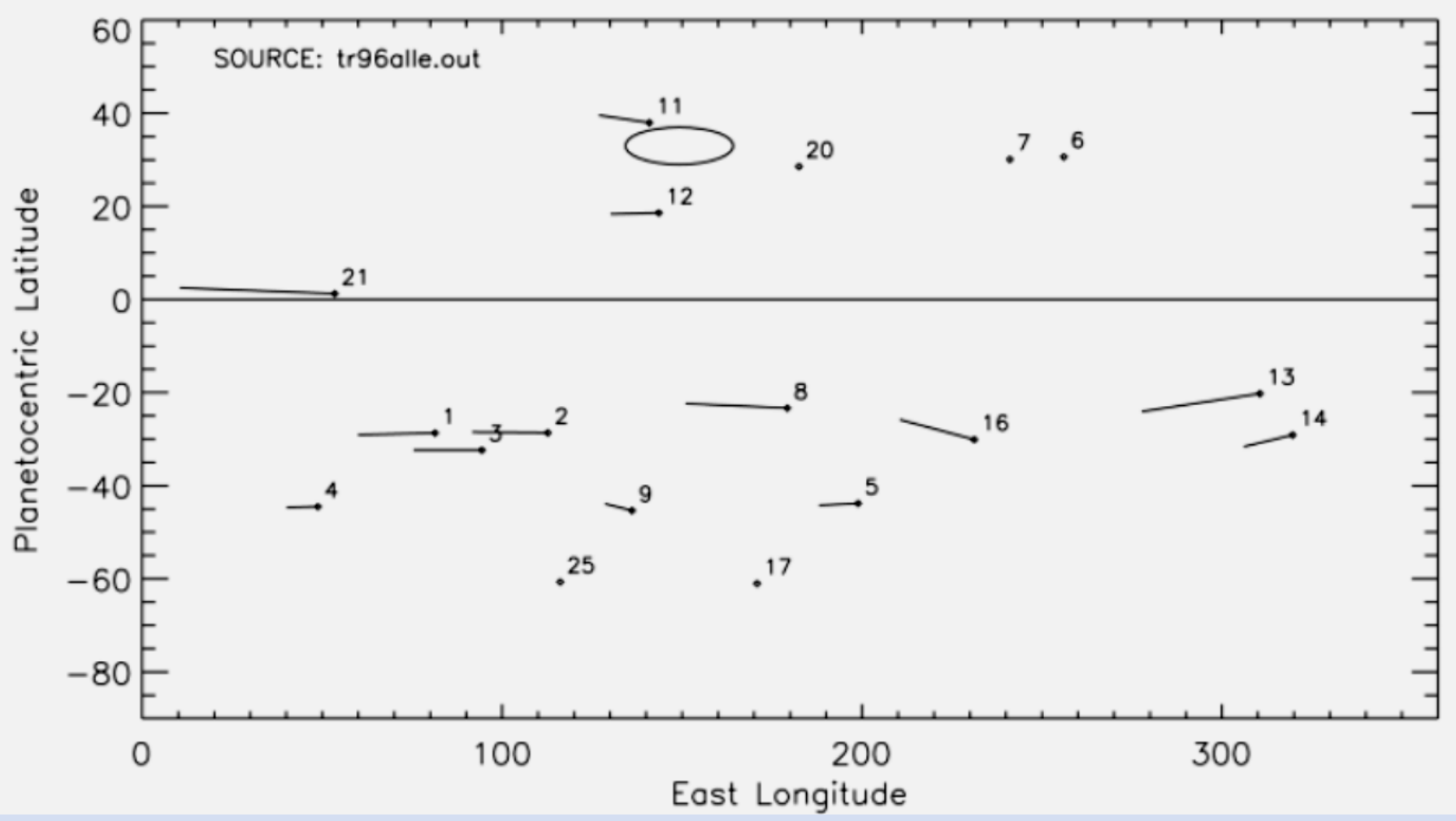

Neptune atmospheric phenomena (Reference 26) 


\section{AMOSS UAV Mission Profiles \\ (Multiple Targets Assessed, One Way)}
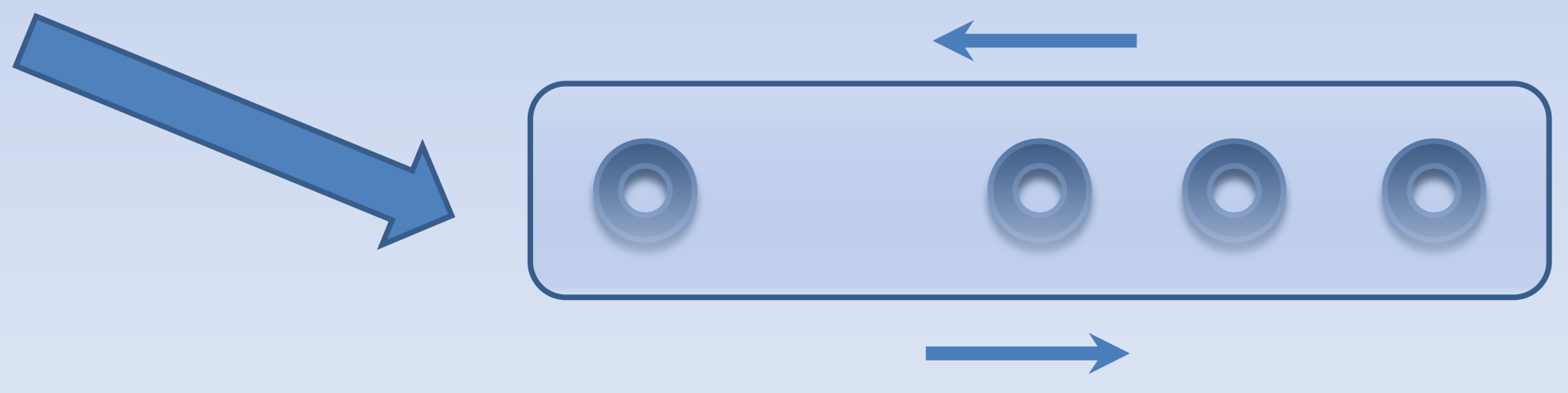


\section{AMOSS UAV Mission Profiles \\ (Multiple Targets Assessed, Round Trip)}

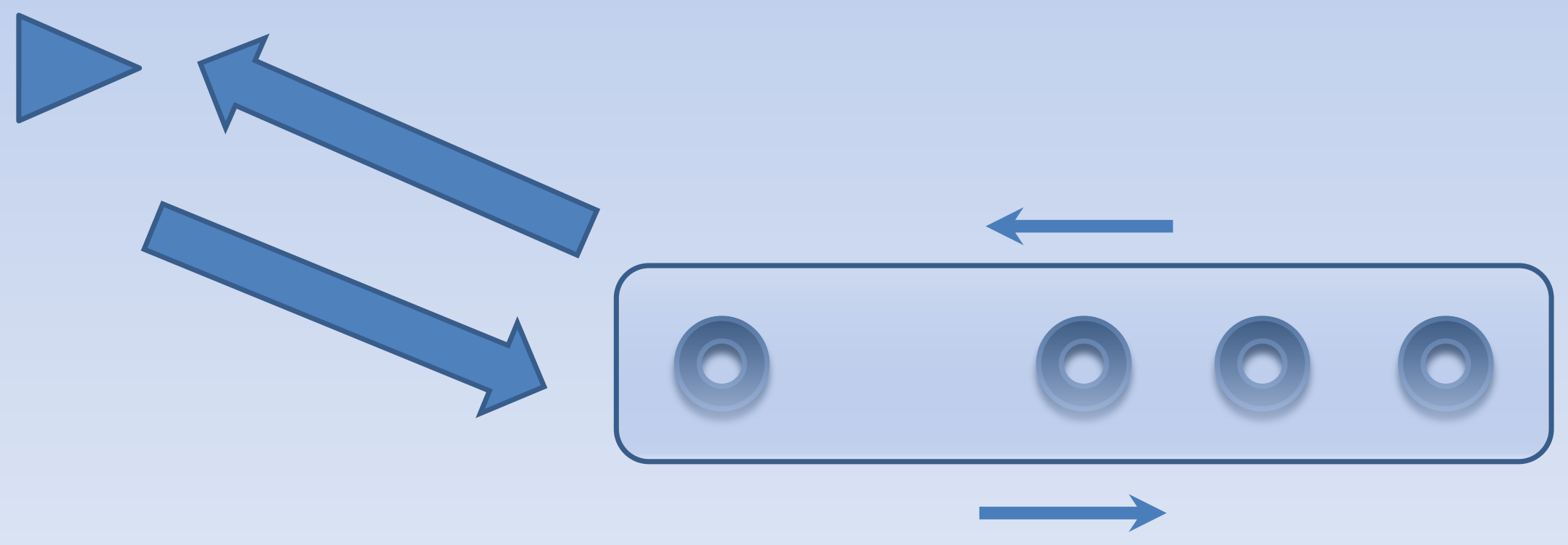




\section{AMOSS UAV Mission Profiles}

(Multiple Targets Assessed, Two Hemispheres, One Way)
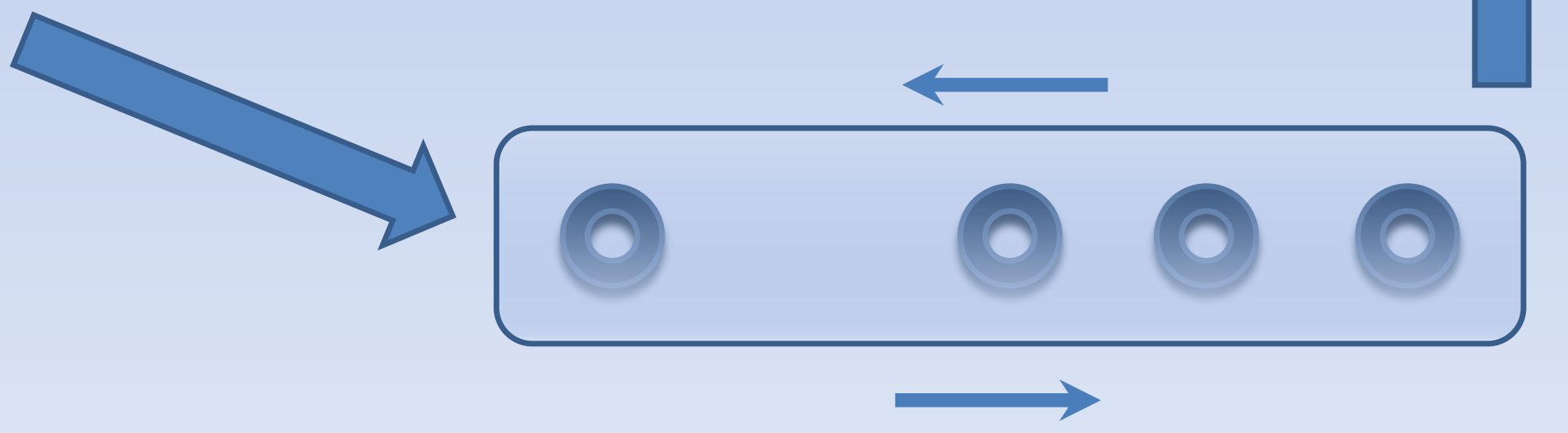


\section{AMOSS UAV Mission Profiles}

(Multiple Targets Assessed, Two Hemispheres, Round Trip)

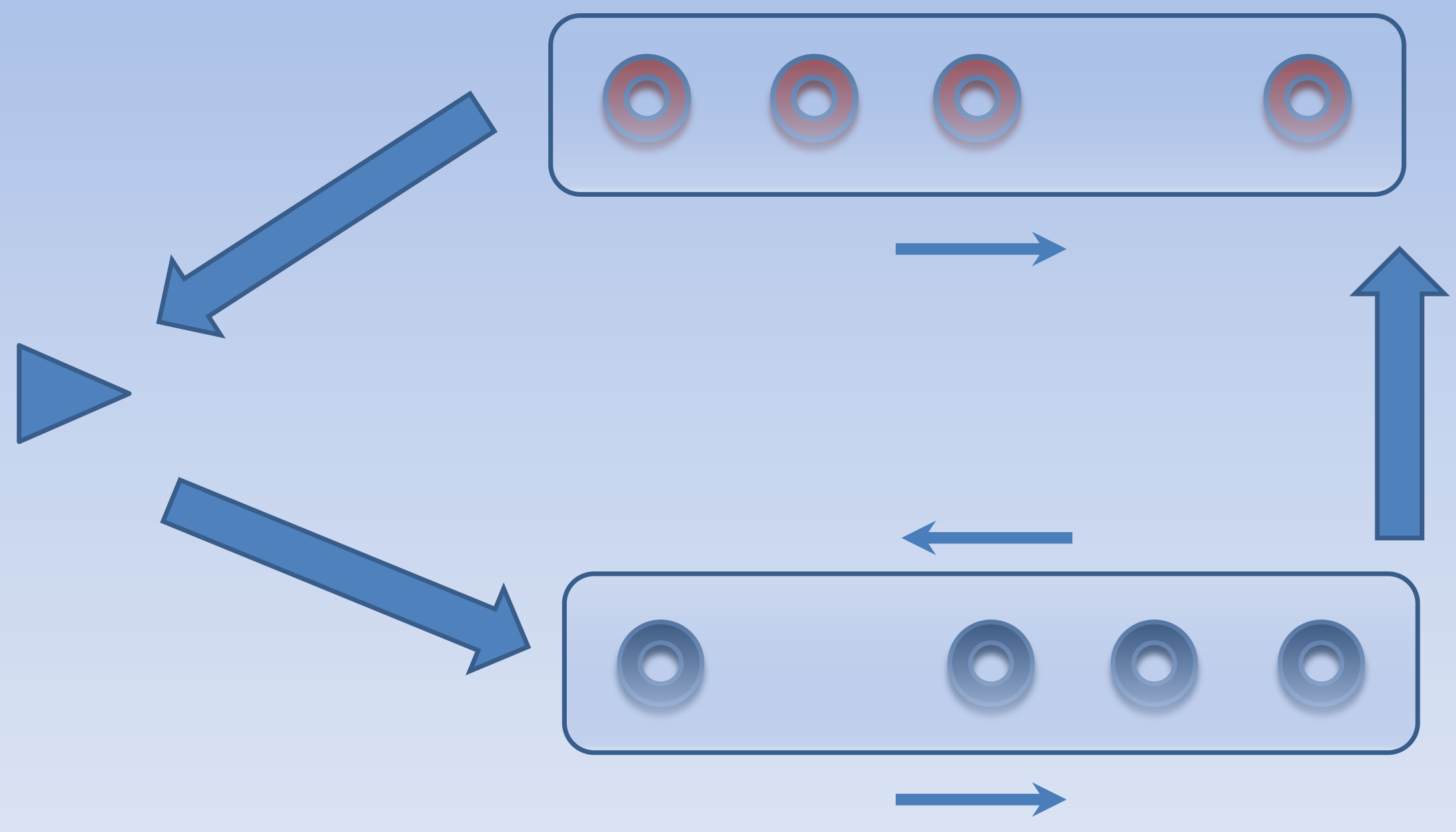




\section{Travel Time Across Planet: Uranus}

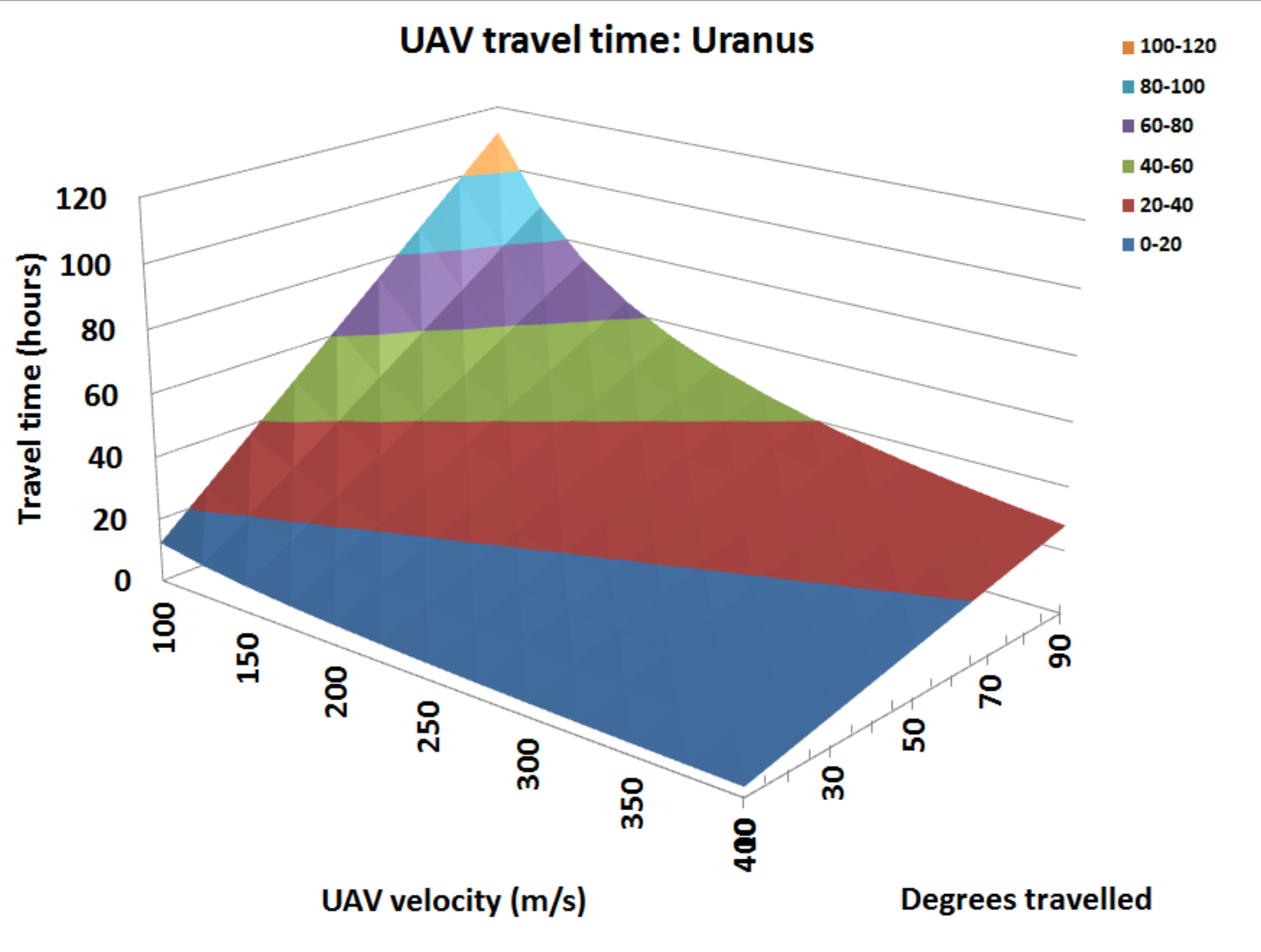




\section{Travel Time Across Planet: Neptune}

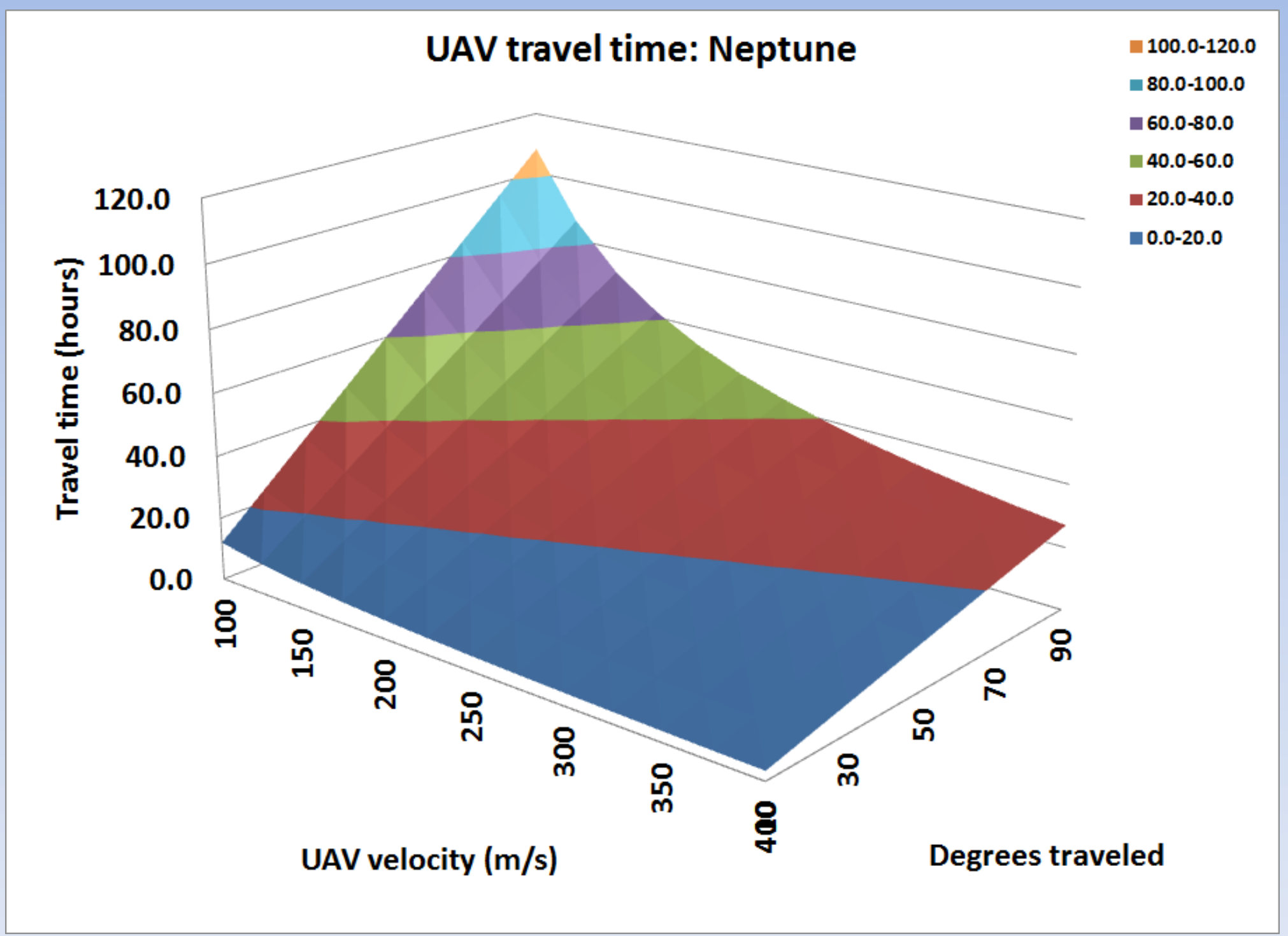




\section{Time for Storm Circumnavigation}

Time for circumnavigation of outer planet atmospheric storms, standoff distance $=\mathbf{1 0 0} \mathrm{km}$

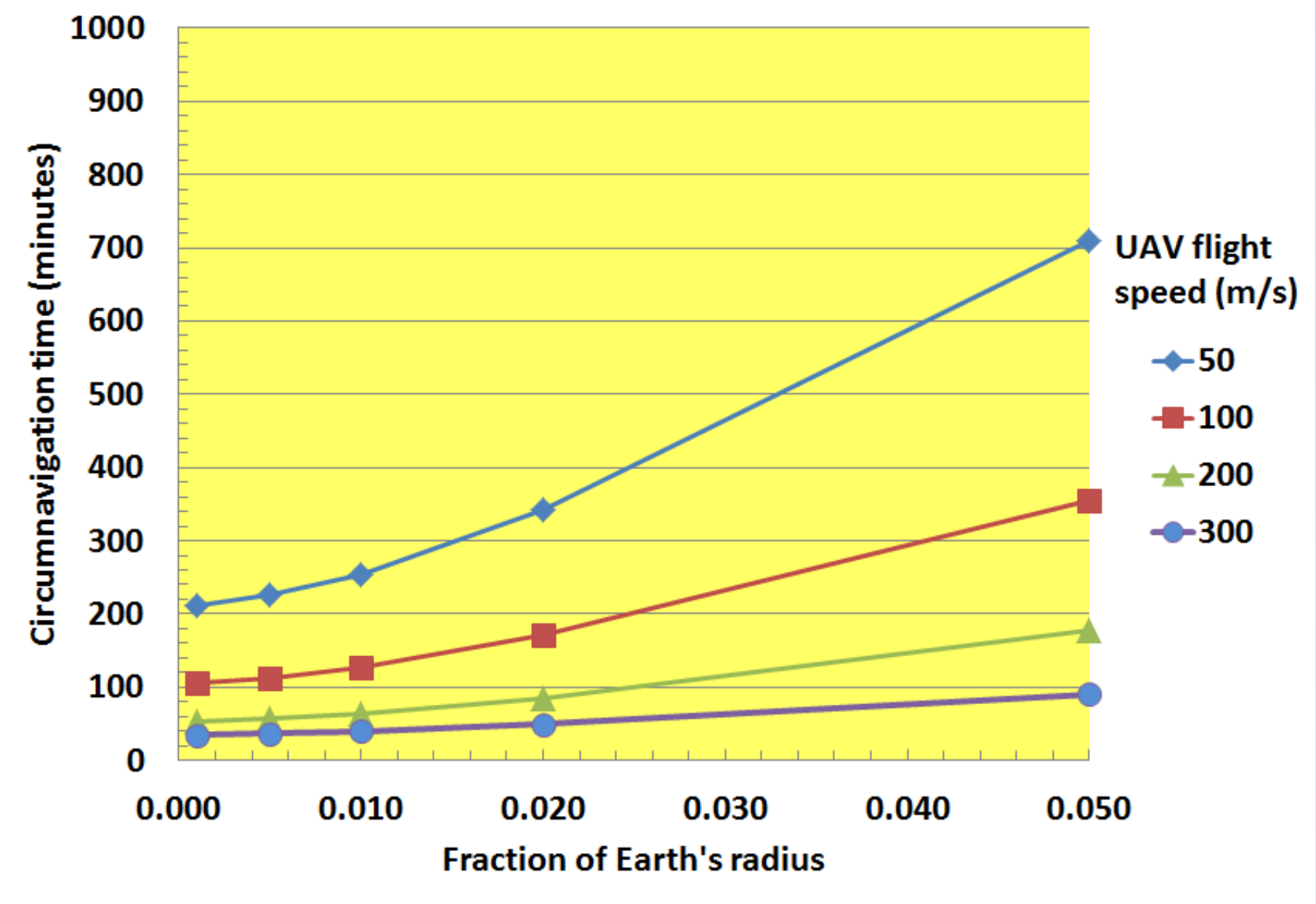




\section{Resource Capturing - Observations (1/2)}

- Helium 3 is the primary gas for capturing by aerospacecraft cruisers.

-While capturing helium 3, the cruiser also has the potential for capturing very large amounts of hydrogen and helium 4 (which comprise nearly $100 \%$ of the atmosphere).

- Resource capturing of hydrogen and helium 4 can lead to fueling fleets of smaller but specialized exploration and exploitation vehicles.

- New concepts for weather monitoring, cloud exploration, and deep-diving aircraft fueled by these large resources are possible. 


\section{Resource Capturing - Observations (2/2)}

- Uninhabited Aerial Vehicle (UAV) and drone options may use nuclear ramjets or rockets.

- Sampling of the atmosphere and investigation of short- and long-term storm and weather related phenomena are options.

- Mission planning could allow for surveying many targets per UAV flight.

- Nuclear thermal propulsion reactor life may limit nuclear ramjet based aircraft to less than $\mathbf{4 0}$ hours.

- Rocket vehicles that deliver the ramjets to storm locations may allow for rapid responses to unique storms and other phenomena. 


\section{Concluding Remarks}

- Atmospheric mining can open new frontiers.

- Gas core engines can reduce the vehicle initial mass by $72 \%$ to $80 \%$ over solid core NTP powered vehicles.

- AMOSS helium 3 capturing leads to processing huge amounts of gas for powering unique UAVs and atmospheric missions.

- Nuclear thermal propulsion reactor life may limit nuclear ramjet aircraft to less than $\mathbf{4 0}$ hours of operation.

- Rocket vehicles that deliver the ramjets vehicles to storm locations may allow for rapid responses to unique atmospheric phenomena.

- Let's go to the stars, as quickly as possible. 